\title{
Generalised stacking fault energy of Ni-Al and Co-Al-W superalloys: Density-functional theory calculations
}

\author{
H. Hasan ${ }^{\mathrm{a}}$, P. Mlkvik ${ }^{\mathrm{b}}$, P. D. Haynes ${ }^{\mathrm{a}}$, V.A. Vorontsova, ${ }^{\mathrm{a}, \mathrm{c}}$ \\ ${ }^{a}$ Department of Materials, Royal School of Mines, Imperial College London, Prince Consort Road, South Kensington, \\ London SW7 2BP, UK \\ ${ }^{b}$ Department of Physics, Blackett Laboratory, Imperial College London, Prince Consort Road, South Kensington, \\ London SW7 2BW, UK \\ ${ }^{c}$ Department of Design, Manufacturing and Engineering Management, University of Strathclyde, JW703, Level 7, \\ James Weir Building, 75 Montrose Street, Glasgow, G1 1XJ
}

\begin{abstract}
Generalised stacking fault energy surfaces ( $\Gamma$-surfaces) are calculated for Co-Al-W-based and $\mathrm{Ni}$-Al-based superalloys from first-principles calculations. A Special Quasi-random Structure is employed in the calculation of the ternary compound, $\mathrm{Co}_{3}(\mathrm{Al}, \mathrm{W})$. Phase field simulations are used to compare dislocation cores present in Co-based and Ni-based superalloys. The higher planar fault energies of the Co-based system lead to a more constricted dislocation which can have implications on both the bowing of dislocations as well as cross-slip. Additionally, planar fault energies of various $\mathrm{L}_{2}$ compounds are compared to explain observed segregation pathways in both types of superalloy. Both the planar fault energies and the segregation pathways are discussed within the context of strengthening mechanisms in superalloys.
\end{abstract}

Key words: superalloys, density functional theory, stacking fault energy, phase field simulation, dislocations

\section{Introduction}

Ni-based superalloys are used in a wide range of applications that require strength and environmental resistance at high temperature. The combination of $\gamma^{\prime}$-precipitates in a $\gamma$-matrix is still the main requirement for a superalloy to exhibit high-temperature strength; especially for those alloys used to manufacture gas turbine blades and discs. The temperatures these components are exposed to are always increasing due to the demand for greater efficiency.

Today Ni-based superalloys are a very mature system and the potential for them to be improved further is diminishing. For instance, high $\gamma^{\prime}$ solvus temperatures have been shown to increase creep resistance [1], but the $\gamma^{\prime}$ solvus temperature of Ni-based superalloys is reaching its limit, which is the eutectic reaction temperature of the $\gamma$ and $\gamma^{\prime}$ phases.

In 2006, Sato et al. [2] obtained the same $\gamma / \gamma^{\prime}$ microstructure in the ternary Co-Al-W system. Co-based superalloys already offered greater environmental resistance and, with the addition of other alloying elements, have the potential to maintain their strength at higher temperatures than Ni-based superalloys. This is especially useful in the fossil fuels energy sector, where the demand to use low grade fuel, with higher sulphur content is growing [3].

Since 2006, there has been a significant concerted effort to understand the various physical and mechanical properties of these alloys. Within that effort, atomistic and continuum scale Preprint submitted to Elsevier 
modelling play an important role. For example, the generalised stacking fault energy (GSFE or $\Gamma$-surface) is a two dimensional energy surface that can give insight into the deformation mechanisms of a material [4]. The relative energies of planar faults, taken from the minima of the GSFE, dictate how dislocations dissociate. Alloys with low stacking fault energies tend to form a larger number of faults, causing a greater accumulation of partial dislocations that can lead to higher ductility and fracture toughness [5].

Additionally, the $\Gamma$-surface can be used as an input for the Phase Field Model for Dislocations (PFMD), which is a continuum approach that describes the motion of dislocations in complex micro-structural systems under applied stress [6]. Here, the $\Gamma$-surface is calculated using first principles calculations. By implementing it in the PFMD [8, 9], one can begin to understand which atomistic mechanisms manifest themselves at microstructural length-scales. This concept has been successfully applied to Ni-based superalloys [10, 11, 12] to study the mechanisms of creep and yield. While, there has been an attempt to create a PFMD description of Co-based superalloys by Feng et al. [13], the authors did not employ a complete first-principles $\Gamma$-surface for $\mathrm{Co}_{3}(\mathrm{Al}, \mathrm{W}) \gamma^{\prime}$ phase. Instead, the study relied on an interpolation of binary $\mathrm{L1}_{2}$-ordered $\mathrm{Co}_{3} \mathrm{Al}$ and $\mathrm{Co}_{3} \mathrm{~W}$ fault energy data and experimentally obtained values. As a simplifications, the authors also used a pure $\mathrm{Ni} \Gamma$-surface for the $\gamma$ matrix phase.

In the present study, we have implemented a tilted cell method [14] to calculate $\Gamma$-surfaces of multiple fcc- $\mathrm{L}_{2}$ compounds. Within the tilted cell method, a more robust scheme is developed to relax the system in contrast to other approaches. The $\Gamma$-surfaces of both the $\gamma$ and $\gamma^{\prime}$ phases of Ni-Al and Co-Al-W-based superalloys have been compared. A Special Quasi-random Structure was employed to calculate the $\Gamma$-surface for the $\gamma^{\prime}$ phase in ternary Co-Al-W alloys. The $\Gamma$-surfaces of multiple $\mathrm{L}_{2}$ ordered, binary compounds are also investigated. The compounds were chosen according to Ni-based and Co-based superalloys currently used in industry. The differences between fault energies are compared to solute segregation pathways that are observed experimentally in deformed alloys. Additionally, the PFMD is used to compare the structure of the dislocation cores found in Ni-Al-based and Co-Al-W-based superalloys.

\section{Methodology}

The $\Gamma$-surface is obtained by cutting a crystal along one of its crystallographic planes and displacing the upper half with respect to the lower half by a displacement vector, $\mathbf{u}$, in the plane. The energy change due to this displacement is then plotted as a two-dimensional surface, $\Gamma(\mathbf{u})$. The Co-based and Ni-based superalloys used in gas turbine engines feature $\mathrm{L}_{2}$ ordered $\gamma^{\prime}$ precipitates embedded in a disordered $\gamma$ phase matrix; both of which are fcc crystals. Therefore, the crystallographic plane of interest for this work is the close-packed $\{111\}$-type plane of the primary slip system and the fault vector, $\mathbf{u}$, is a superposition of the orthogonal coplanar vectors

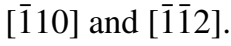

The $\Gamma$-surface was first conceptualised by Vitek [4] to investigate stacking fault stability in bcc crystals by using a central force interaction in a hard sphere model. Since $1970, \Gamma$ surfaces have been calculated using either density functional theory (DFT) [15, 16, 17] or parameterised force field methods [18, 19, 20]. The materials investigated in this study include binary and ternary intermetallics for which accurate interatomic potentials are not presently available. Hence, the total energies of supercells were calculated using DFT, as implemented within the CASTEP (16.1) code [21].

CASTEP is a plane wave code that implements ultrasoft pseudopotentials [22], which replace the core electrons in any system, allowing fewer electrons to be treated explicitly. The generalised 
gradient approximation, parameterised by Perdew, Burke and Ernzerhof (PBE) [23], was used for the exchange correlation functional. The functional is an approximation of the energy of exchange and correlation between electrons [24]. The $k$-point spacing for all calculations was $0.08 \AA^{-1}$. For the supercell example shown in Figures 1 and $1 \mathrm{~b}$, this $k$-point spacing would translate to a mesh of $31 \times 31 \times 6$ (for a six layer cell). The integration across the Brillouin zone used the Methfessel-Paxton energy band smearing method [26], in which the smearing width was $0.1 \mathrm{eV}$. The kinetic energy cut-off was set to $500 \mathrm{eV}$. The aforementioned DFT parameters were chosen after conducting convergence tests that were to reduce the error of any stacking fault energy to $1.0 \mathrm{~mJ} / \mathrm{m}^{2}$. Most of the simulations were non spin-polarised, but some some spinpolarised calculations were also carried out to investigate if any critical differences exist for the $\gamma$ and $\gamma^{\prime}$ phases. Generally, at the high operating temperatures of superalloys, the magnetic moment is reduced to zero. The addition of $\mathrm{Cr}$, which is required for oxidation and corrosion resistance, to both Co-based and Ni-based superalloys also results in a marked loss of magnetisation [28].

The supercell orientation relative to the crystal axes and relaxation scheme are illustrated schematically for a single component fcc crystal in Figure 1 . The cell axes $x, y$ and $z$ are parallel to the $[\overline{1} 10],[\overline{1} 01]$ and [111] crystallographic axes respectively. For simplicity, a cell with six (111) planes is presented, showing the characteristic fcc stacking sequence of ABC. It should be noted that, for an $\mathrm{L}_{2}$-fcc crystal, four atoms per plane are required. In order to displace the upper half with respect to the lower half, the $\mathbf{a}_{3}$ lattice vector is tilted by a displacement vector, $\mathbf{u}=(x, y, 0)$, which is perpendicular to the original $z$-axis. This creates a single planar fault at the top and bottom of the cell due to periodic boundary conditions. The two orthogonal shift directions were $\langle 112\rangle$ and $\langle 110\rangle$ type shifts. For fcc crystals the effective shift vectors were fractions of $\frac{a}{2}[\overline{2} 11]$ and $\frac{a}{2}[\overline{1} 01]$, while for $\mathrm{L}_{2}$ crystals, the effective shift vectors were fractions of $a[\overline{2} 11]$ and $a[\overline{1} 01]$

Due to the periodic boundary conditions, the planar faults must be elastically isolated. Trial simulations were carried out using fcc $\mathrm{Ni}$ to determine the minimum number of layers to achieve this. Intrinsic and unstable stacking fault (ISF and $\mathrm{USF}_{2}$ ) energies were calculated for cells with 6, 9, 12 and 15 (111) layers and it was conluded that a minimum of six layers were needed to avoid significant image effects form periodicity. The corresponding data are presented in in Table 2. Where resources allowed for it, nine layer cells were used for the subsequent simulations for the A1 $\gamma$ (9 atoms per cell) and the $\mathrm{L}_{2} \gamma^{\prime}$ phases (36 atoms per cell). The $\mathrm{Co}_{3}(\mathrm{Al}, \mathrm{W})$ supercell was limited to six (111) layers, because the adequate randomisation of $\mathrm{Al}$ and $\mathrm{W}$ crystallographic sites while maintaining the correct overall stoichiometry required a minimum of 96 atoms, with 16 atoms per (111) layer. In view of both time and computational resource constraints of the research project, using nine-layer supercells with 144 atoms was not practically possible for $\mathrm{Co}_{3}(\mathrm{Al}, \mathrm{W})$. The supercell files used for the simulations are provided in the supplementary information.

Since the energy of a tilted cell is being compared to that of a non-tilted cell, there exists a lack of equivalency in $k$-point sampling. As such, a test was performed on multiple systems whereby the energy of a perfect crystal was compared to that of a system in which the $a_{3}$ axis was tilted by $a[\overline{2} 11]$, which is a vector joining two equivalent atomic sites within the same (111) plane. Table 3 shows that the error resulting from inequivalent $k$-point sampling is small, less than $1 \mathrm{~mJ} / \mathrm{m}^{2}$.

Once a fault is introduced into a supercell, the system must be relaxed in the direction perpendicular to the fault before extracting a final energy. Both the positions of the atoms and the length of the supercell must be optimised. Firstly atomic positions are relaxed to minimise the out of 
plane forces to less than $10 \mathrm{meV} / \AA$. Then, the volume of the supercell must be optimised while keeping the fractional positions of the atoms constant. Between five and six cells are created with different [111] axis lengths. The range of these lengths must be chosen so that an optimum length which minimises the energy is included. The calculated energies of these cells are then fitted to a parabolic curve, of the form $y(x)=c_{2} x^{2}+c_{1} x+c_{0}$. The minimum of this curve is taken as the new [111] axis length and the atomic positions are relaxed again. This process is continued until the change in fault energy is less than $1 \mathrm{~mJ} / \mathrm{m}^{2}$ and the out of plane forces on all atoms are less than $10 \mathrm{meV} / \AA$, as shown in Figure 1. The parabolic polynomial was chosen because it is the simplest function capable of providing a good fit. There were no practical benefits using alternative more complex methods, such as equations of state, as their use would not affect the end result.

There exist two other options when calculating $\Gamma$-surfaces using the supercell approach in DFT codes that implement periodic boundary conditions. Both options offer simpler relaxation schemes, but require larger supercells. Two bulk slabs can be displaced with respect to each other to create a fault on the displacement plane. However, sufficient vacuum is required to ensure only one type of fault is created. The vacuum also creates free surfaces that must be treated carefully [40, 15]. Alternatively, three bulk slabs can be slid with respect to one another to create three identical faults which requires a very large supercell [29]. Hence, the tilted cell approach was chosen, as it allows for the smallest supercell to be used.

Rather than mapping out the entire surface, energy calculations were performed only on specific points that take advantage of the symmetry of the $\Gamma$-surface. These points are shown in Figure $1 \mathrm{~d}$ and their energies are numerically fitted by a two-dimensional Fourier series, $\Gamma(x, y)$, using the approach of Schoeck [30]. More details, such as the equation used for the Fourier Series, can be found in the supplementary information.

Calculating a $\Gamma$-surface for the ternary compound, $\mathrm{Co}_{3}\left(\mathrm{Al}_{0.5}, \mathrm{~W}_{0.5}\right)$ is not straightforward. In the $\mathrm{L}_{2}$ lattice, the Co atoms tend to occupy the face centre sites, whereas the $\mathrm{Al}$ and $\mathrm{W}$ atoms are randomly distributed among the corner sites, as confirmed by X-ray crystallography [2]. The random occupancy of the corner sites poses a problem for periodic-cell DFT calculations. Using periodic structures to describe a random system introduces spurious correlations beyond a certain length scale [31]. These periodicity errors can be overcome with supercells that have a large number of atoms so that interactions between atoms and their periodic images are minimised. Otherwise, the "virtual crystal approximation" can be utilised, where the Al and W atoms are combined to form an averaged type of atom [32]. When calculating $\Gamma$ surfaces for a compound, the individual atom relaxations near the fault plane play a significant role in the energy of the compound. Therefore, the VCA is not appropriate in distinguishing the separate relaxations of the $\mathrm{Al}$ and $\mathrm{W}$ atoms. It has been shown by Tegner et al. [33] that the VCA works well for chemical elements across a row of the periodic table, but not for elements that are far apart, such as $\mathrm{Al}$ and $\mathrm{W}$. Converging the self consistent field loop during a DFT calculation is very difficult in such cases.

On the other hand, Special Quasi-random Structures (SQSs) can be implemented. These are smaller supercells, described by a configuration parameter, $\sigma$. SQSs reproduce the properties of an infinite, random cell up to a chosen length scale. To produce an SQS, the correlation functions, $\bar{\prod}_{k, m}(\sigma)$, are calculated for different configurations and compared to the correlation functions of a random cell, which are zero. The configuration that most closely resembles a random cell is chosen as the supercell for subsequent DFT calculations. The SQS supercell in Figure 2 was obtained using the ATAT code [34, 35, 36, 37, 38] and its correlation functions are compared to those of a random cell in Table 1. 
There exist multiple choices of fault plane when calculating an SQS $\Gamma$-surface. In the $\mathrm{L}_{2}$ $\mathrm{A}_{3} \mathrm{~B}$ crystal, there are three possible bonds possible between the nearest neighbour B-sublattice atoms that can be present across the fault plane: Al-Al, W-W and Al-W. Figure 2 characterises each of the six potential fault planes by counting the number of each type of bond across each possible fault plane for the SQS supercell. The $\Gamma$-surfaces of fault planes 2, 4 and 6 were calculated since these planes capture the range of possible $\mathrm{Al}$ and $\mathrm{W}$ interactions. I.e. fault plane 2 gives a balanced contribution from both like and dissimilar atom pairs, while planes 4 and 6 exclude contributions from $\mathrm{Al}-\mathrm{Al}$ and $\mathrm{W}-\mathrm{W}$ bonds respectively.

Using the calculated $\Gamma$-surfaces, the PFMD can be employed to investigate the difference in the core structure for dislocations present in both the $\gamma$ and $\gamma^{\prime}$ phases. For this purpose, the approach developed by Wang et al. [6] was used, which uses the Khachaturyan-Shatalov [7] elastic inclusion theory to describe the strain energy of the fields. Field variables representing displacement magnitude along the dislocation Burgers vectors are used to calculate the total free energy of the system. This total energy has three contributions: the crystal energy ( $\Gamma$-surface), the gradient energy and the elastic energy. The Shen and Wang formulation was used for the core energy components (i.e. the crystal and gradient energies) [8, 9]. More detail regarding the free energy formulation is provided in the supplementary information.

For the PFMD calculations, simulation cells were set up so that its the orthogonal axes $x, y$ and $z$ were parallel to the $[10 \overline{1}],[10 \overline{1}]$ and $[1 \overline{2} 1]$ crystallographic directions respectively. The dimensions of the cells were $220 \times 32 \times 1$ voxels respectively. Since the elastic energy is solved in reciprocal space using Fast Fourier Transforms, periodic boundary conditions apply. Thus, the $x$ and $y$ system dimensions were chosen such that the elastic image forces on the dislocation slip field were reduced to a negligible minimum. The simulation volume was set up as entirely single phase (i.e. either all $\gamma$ or all $\gamma^{\prime}$ ) using the corresponding $\Gamma$-surface functions in the crystal free energy and the corresponding elastic constants (assuming elastic homogeneity).

Table 4 summarises the material properties that were used for the PFMD calculations including the anisotropic elastic constants $c_{11}, c_{12} c_{44}$ and the lattice parameters $a$. The elastic constants were normalised with respect to the grid size of the system which is $a / \sqrt{3}$.

A field corresponding to the $\frac{a}{2}[10 \overline{1}]$ displacement was introduced parallel to the (111) plane into the $\gamma$ phase simulations, and the displacement was doubled to $a[10 \overline{1}]$ for the $\gamma^{\prime}$ phases. The slip field effectively created an infinite edge dislocation dipole that was stable. No external stress was applied to the system and the dislocation cores were allowed to relax until they reached equilibrium. The dislocation line energy was then integrated using the gradient and crystal free energy contributions.

\section{Results \& Discussion}

\section{1. $\gamma$-phase calculations}

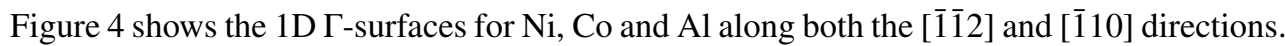
Table 5 contains the specific values of the intrinsic stacking fault (ISF) and unstable stacking fault $\left(\mathrm{USF}_{1}\right)$ energies, as calculated here and in other studies.

The approach used in this investigation can be referred to as a bulk geometry method. The alternative slab geometry method uses a slab of atoms with vacuum above and below. For pure fcc-Ni, $\Gamma_{\text {ISF }}$ was calculated to be $153 \mathrm{~mJ} / \mathrm{m}^{2}$ which is in good agreement with the Chandran and Sondhi [39] value of $159 \mathrm{~mJ} / \mathrm{m}^{2}$. Those authors used a bulk geometry and $14\{111\}$ type planes 
to separate the ISF from its periodic image. The $k$-point mesh used was also similar to the present work.

All other ISF energies for fcc-Ni from the cited literature were calculated using a slab geometry and differ from the present work. The Zimmermanet al. [40] and Rosengaard and Skriver [41] calculation methods were not explained in much detail. However, both used smaller cells with 6 and 8 layers respectively. Siegel $\left(110 \mathrm{~mJ} / \mathrm{m}^{2}, 10\right.$ layers $)$, Brandl et al. $\left(137 \mathrm{~mJ} / \mathrm{m}^{2}\right.$, 12 layers) and Hunter et al. (145 mJ/m², 16 layers) used larger cells and the number of layers used shows that the larger the cell, the closer the calculated ISF energy is to the value obtained in this study $\left(153 \mathrm{~mJ} / \mathrm{m}^{2}\right)$. Both Siegel and Brandl et al. also calculated the fcc-Ni $\Gamma_{\mathrm{USF}_{1}}$ to be $273 \mathrm{~mJ} / \mathrm{m}^{2}$ and $278 \mathrm{~mJ} / \mathrm{m}^{2}$, respectively, which is in very good agreement with the present work value of $275 \mathrm{~mJ} / \mathrm{m}^{2}$.

For fcc-Co, no $\Gamma$-surfaces could be found in the existing literature at the time of this writing. This is most likely due to the fact that pure Co assumes the fcc crystal only at elevated temperatures (i.e. above $422^{\circ} \mathrm{C}$ [cite]). The most recent calculation of the ISF energy in fcc-Co was carried out by Rosengaard and Skriver [41]. The authors were investigating the relationship of $\Gamma_{\text {ISF }}$ to the structural energy differences between hcp and fcc phases for $3 d, 4 d$ and $5 d$ transition metals. The method used by the authors was based on the linear muffin tin orbital approach within the tight-binding approximation. Therefore, the comparison of $\Gamma_{\text {ISF }}$ with the present work may not be fruitful. However, the trends could be. Rosengaard and Skriver's $\Gamma_{\text {ISF }}$ for fcc-Co was greater than that for fcc-Ni, which matches the present work proportionally. In their investigation, the authors were able to show that $\Gamma_{\mathrm{ISF}} \approx 2 \mathrm{E}_{h c p-f c c}$, where $\mathrm{E}_{h c p-f c c}$ is the structural energy difference between hcp and fcc structures and this is reportedly a result of the short range nature of the transition metal $d$-state bonding.

When an ISF is introduced into an fcc crystal, the stacking sequence of the crystal changes from ...ABCABC... to ...ABC|BCA..., where '|' marks the position of the fault. The short range bonding near the fault does not change as the fault is introduced, except in the dihedral angle between nearest neighbour atoms [15]. This change in the dihedral angle affects the $d$-state $\pi$ type and $\delta$-type bonding which become increasingly important in more open shell systems. The electronic configurations of $\mathrm{Ni}$ and $\mathrm{Co}$ are $[\mathrm{Ar}] 4 \mathrm{~s}^{2} 3 \mathrm{~d}^{8}$ and $[\mathrm{Ar}] 4 \mathrm{~s}^{2} 3 \mathrm{~d}^{7}$ respectively and so one could expect a higher $\Gamma_{\mathrm{ISF}}$ for $\mathrm{Co}$.

The consistently higher energy $\Gamma$-surface of Co, shown in Figure 4 , implies that dislocations in the $\gamma$-phase of a Co-based superalloy would tend to be more constricted than in Ni-based superalloys. This is confirmed when considering the relaxed dislocation cores of both $\mathrm{Ni}$ and $\mathrm{Co}$ in the $\gamma$ phase as shown by phase field model simulations which are discussed later on.

For fcc-Al, $\Gamma_{\text {ISF }}$ was calculated to be $122 \mathrm{~mJ} / \mathrm{m}^{2}$ which is in good agreement with the $\Gamma_{\text {ISF }}$ calculated by Woodward et al. [42] $\left(124 \mathrm{~mJ} / \mathrm{m}^{2}\right)$. This is surprising, since Woodward et al. modelled edge and screw dislocations using DFT. The resulting distances between Shockley partial dislocations were then used to calculate an ISF energy for fcc Al. On the other hand, Lu et al. [43] used a slab geometry of 9 layers. The ISF energy of $164 \mathrm{~mJ} / \mathrm{m}^{2}$ is $34 \%$ greater than the present study. The $k$-point grid used in that work was similar to the present work. However, the kinetic energy cut off was only $150 \mathrm{eV}$ and the forces between atoms in the supercells were converged to $2.5 \times 10^{-2} \mathrm{eV} / \AA$, which could explain the difference between ISF values.

The non spin-polarised calculations show that the ISF energy of fcc-Co is greater than the ISF energy of fcc-Ni. However, further analysis is beneficial since both elements are ferromagnetic. The introduction of an ISF on a $\{111\}$ plane in an fcc crystal creates a hep region within the crystal. At zero-temperature, Co tends to exhibit a hcp structure. Since the DFT calculations described here also assume $0 \mathrm{~K}$, one would expect the Co ISF energy to be negative. Therefore, 
spin-polarised calculations were performed for fcc-Co and fcc-Ni for two points on the $\Gamma$ surface: ISF and $\mathrm{USF}_{1}$. To isolate the effect of spin, $\Gamma$ surface energies were simple energy calculations that did not involve any relaxation of atomic position or cell volume. Since no relaxation was involved, the non spin-polarised energies were also calculated.

The results of the calculations are shown in Table 6 The magnetic moments shown for both $\mathrm{Co}$ and Ni match those found in other studies [44, 45]. The lattice parameters for the spinpolarised systems were calculated by fitting energy volume curves to a continuous function based on the Birch-Murnaghan equation of state [57]. The change due to spin in the lattice parameter for fcc-Co is much greater than the change for fcc-Ni. Non spin-polarised calculations were carried out for the new lattice parameters to further isolate the effect of magnetism. In fcc-Co, the ISF energy decreased by $9 \%$, whereas the $\mathrm{USF}_{1}$ energy is reduced by $65 \%$, implying that the new geometry has a much greater effect on the $\mathrm{USF}_{1}$ energy.

However, by including the effect of magnetism, the ISF energy of fcc-Co is significantly reduced from $154 \mathrm{~mJ} / \mathrm{m}^{2}$ to $-100 \mathrm{~mJ} / \mathrm{m}^{2}$. The energy difference between spin polarised and non spin-polarised fcc-Co is $0.15 \mathrm{eV} /$ atom, calculated by taking the difference of minimum energy in the energy volume curves for spin polarised and non spin-polarised fcc-Co. Assuming an operating temperature of the gas turbine engine to be $1000 \mathrm{~K}$, thermal energy can be approximated as $\mathrm{E} \sim \frac{3}{2} k_{B} T \sim 0.13 \mathrm{eV} /$ atom. Given the balance between the energy differences due to spin and thermal energy, the ISF energy of spin-polarised fcc-Co in a gas turbine engine is expected to be in between the ISF energies for spin polarised and non spin-polarised fcc-Co. On the other hand, fcc-Ni shows a much smaller change in both ISF and $\mathrm{USF}_{1}$ energy when electron spin is considered.

\section{2. $\gamma^{\prime}$-phase calculations}

Three examples of two-dimensional $\Gamma$-surfaces are shown in Figure 3 for $\mathrm{Ni}_{3} \mathrm{Al}, \mathrm{Co}_{3} \mathrm{Ti}$ and $\mathrm{Co}_{3}(\mathrm{Al}, \mathrm{W})$. These three compounds are all stable $\mathrm{L}_{2}$ crystal structures. Various dislocation dissociation paths are shown along with local minima, each corresponding to a specific planar fault. The general topography of all three $\Gamma$-surfaces is similar, but the difference in planar fault energies can lead to different $\gamma^{\prime}$ shearing mechanisms during plastic deformation.

Table 7 shows the various planar fault energies for the $\gamma^{\prime}$ phases found in $\mathrm{Ni}-\mathrm{Al}$ and $\mathrm{Co}-$ $\mathrm{Al}-\mathrm{W}$ superalloys. The planar fault energies for $\mathrm{Ni}_{3} \mathrm{Al}$ are in general agreement with the values from literature. The SISF energies calculated by Myrasov et al. [46] $\left(80 \mathrm{~mJ} / \mathrm{m}^{-2}\right)$ and Schoeck et al. [47] $\left(79 \mathrm{~mJ} / \mathrm{m}^{-2}\right)$ fall within $9 \%$ of the present work $\left(74 \mathrm{~mJ} / \mathrm{m}^{-2}\right)$. Both studies used the local density approximation for the exchange correlation functional employed in DFT. The bulk crystal method was used, but only six atomic layers separated the fault plane from its periodic image. Despite these differences, there is good agreement only for the SISF energy with Myrasov et al. and Schoeck et al. On the other hand, the APB and CSF energies calculated by both groups differ by up to $40 \%$ when compared the present work values of 162 and $191 \mathrm{~mJ} / \mathrm{m}^{-2}$ respectively. This is most likely due to the greater extent to which the current system has been relaxed, hence producing lower CSF and APB energies. The SISF energy requires little relaxation since the change to the structure upon the creation of a SISF is to the third nearest neighbour.

Vamsi and Karthikeyan's [48] DFT calculations for planar fault energies of $\mathrm{Ni}_{3} \mathrm{Al}$ were similar to the present work. Both the APB and CSF energies agree to within 11\%. However, the SISF energy differs by $48 \%$. The only difference in this work was the number of layers that separated the fault plane from its periodic image. The authors used six planes, whereas nine planes were used here. Additionally, only atomic relaxation was permitted, whereas the simulations in this work also relaxed the [111] cell vector, perpendicular to the fault plane. This is also the case 
with the fault energy values obtained by Rao et al. [72]. The APB and CSF energies are within $10 \%$, while the SISF energy of $37 \mathrm{~mJ} / \mathrm{m}^{-2}$ differs by $50 \%$ and is closer to the value obtained by Vamsi and Karthikeyan. Raoet al. [72] used a 12-layer 192 atom supercell, the tilted cell method for creating faults and took into account spin-polarisation. Thus, electron spin appears to affect SISF energy in $\mathrm{Ni}_{3} \mathrm{Al}$ more than the other higher-energy faults $\mathrm{ABP}$ and CSF.

The $\Gamma$-surface data of the three chosen fault planes in $\mathrm{Co}_{3}\left(\mathrm{Al}_{0.5}, \mathrm{~W}_{0.5}\right)$ calculated without spin-polarisation are plotted in blue in Figure 5 with the continuous line showing the average Fourier series fit. Each fault plane in the SQS, shown in Figure 2, can be characterised by three numbers, $N_{\mathrm{AL}-\mathrm{AL}}: N_{\mathrm{W}-\mathrm{W}}: N_{\mathrm{AL}-\mathrm{W}}$, where $N_{\mathrm{X}-\mathrm{Y}}$ is the number of bonds between nearest neighbour B-sublattice elements $X$ and $Y$ across the fault plane. The bond ratios of fault planes 4 and 6 are 6:0:6 and 0:6:6 respectively and therefore define a range for the $\Gamma$-surface of $\mathrm{Co}_{3}\left(\mathrm{Al}_{0.5}, \mathrm{~W}_{0.5}\right)$. The average $\Gamma$-surface of all three fault planes closely matches that of fault plane 2 , for which the bond ratio is 3:3:6 and hence closely resembles the stoichiometry of the system.

To verify the non spin-polarised data, additional DFT calculations were performed with spinpolarisation enabled. These were initialised with ferromagnetic order on the Co atoms of 1.66 $\hbar / 2$. The spin was relaxed after 10 iterations. For the SISF the total spin was observed to decrease very significantly and so the total spin was further relaxed from close to zero in order to find the lowest energy state. The net spin of the SQS fluctuated between 20 and $60 \hbar / 2$ for the faulted structures and converged to a value of $14.35 \hbar / 2$ in the perfect crystal. The resulting $\Gamma$-surface data are plotted using red in Figure 5 with the continuous line showing the average Fourier series fit.

The planar fault energies for $\mathrm{Co}_{3}\left(\mathrm{Al}_{0.5}, \mathrm{~W}_{0.5}\right)$ are shown in Table 7 and compared to literature values. The standard deviation for each fault energy is also presented. One can see that there is a large dispersion in the values of the fault energies which indicates that the local chemistry near the fault is significant. There is good agreement between the non spin-polarised and spinpolarised data, as can be seen from Figure 5 and Table 7 Spin-polarised calculations generally yielded a lower overall $\Gamma$-surface (GSF energy), with one exception. The SISF energy, although within the range of error, is actually greater for the spin-polarised calculations. This suggests that the zero-spin state is energetically favourable in the SISF. It is also worth bearing in mind that the total energy of the SISF system is the same for both magnetic and non-magnetic simulations. However, the lower total energy of of the perfect crystal obtained using spin-polarised calculations (which is subtracted for the former to obtain the fault energy) results in a higher SISF energy.

Saal et al. [49] used a bulk geometry method, that is almost identical to this work, when calculating the antiphase boundary (APB) energy. However, the system was not random. There was an ordered configuration for $\mathrm{Al}$ and $\mathrm{W}$ atoms along the [001] direction and the calculations were spin-polarised. These differences to the present work do explain the discrepancy in the calculated APB energies of Saal et al. $\left(261 \mathrm{~mJ} / \mathrm{m}^{-2}\right)$ and the present work $\left(425 \pm 123 \mathrm{~mJ} / \mathrm{m}^{-2}\right)$. However, the authors' APB energy value does fall close to the lower range of the APB energies calculated in this work. Additionally, the authors concluded that the local chemistry and configuration of $(\mathrm{Al}, \mathrm{W})$ atoms near the APB fault plane were more important than the bulk chemistry and configuration.

Mottura et al. [50] used the Axial Next Nearest Neighbour Interaction (ANNNI) model to calculate the superlattice intrinsic stacking fault (SISF) energy and the authors' DFT calculations were also spin-polarised. The ANNNI model relates the SISF energy to differences in bulk energy of different crystal structures. It is effective for calculating the SISF energy, but cannot be used to compute the other points in the $\Gamma$ surface. The authors' upper value of the SISF energy 
$\left(93 \mathrm{~mJ} / \mathrm{m}^{2}\right)$ is out of the range of the SISF energy values calculated using the SQS. This deviation from the calculated value of $167 \pm 70 \mathrm{~mJ} / \mathrm{m}^{2}$ could be due to the exclusion of electron spin in the DFT calculations in this work.

The fault energy trend of Vamsi's [51] calculations for $\mathrm{Co}_{3}(\mathrm{Al}, \mathrm{W})$ is $\Gamma_{\mathrm{SISF}}<\Gamma_{\mathrm{CSF}}<\Gamma_{\mathrm{APB}}$, which agrees with the trend shown in the present work. However, the values of the individual fault energies differ from the present work. Vamsi [51] also calculated the fault energies using a bulk geometry method. However, the calculations were spin-polarised and the fault energies of multiple quasirandom structures were averaged. Unfortunately, the spreads of values for the fault energies were not given and, as such, a comparison of that spread cannot be made. However, taking into account the spread of fault energy values in this work, the Vamsi values do fall within $5 \%$ of the lower range of calculated planar fault energies.

Figure 6 shows a higher energy $\Gamma$-surface for the Co-based system when compared to the $\mathrm{Ni}$-based system, similar to the results for the $\gamma$-phase. Greater fault energies and higher barriers between local minima (planar faults) imply that dislocations encounter increased resistance when shearing the $\gamma^{\prime}$ precipitate causing dislocation build up at the $\gamma / \gamma^{\prime}$ interfaces.

Experiments have shown different shearing mechanisms during the primary creep of $\mathrm{Ni}$ based and Co-based superalloys. For temperatures above $850^{\circ} \mathrm{C}$, APB coupled $a / 2\langle 110\rangle$ shearing mechanisms dominate the shearing of the $\gamma^{\prime}$ phase in Ni-based alloys [52, 53]. On the other hand, Titus et al. [54] showed that stacking fault shear was more common in the $\gamma^{\prime}$ phase of Co-based superalloys for temperatures above $850^{\circ} \mathrm{C}$. The $\gamma^{\prime}$ shearing mechanisms are not significantly affected by precipitate size, volume fraction or morphology since these features are similar in both types of alloys. Instead, the planar fault energies must play a determining role. At these high temperatures, the APB energy of Ni-based superalloys is likely lower than the SISF energy of Co-based superalloys. The results presented here also show this trend in Table 7, albeit at 0K.

\subsection{Phase field model simulations}

The PFMD was used to compare dislocation cores in both the $\gamma$ and $\gamma^{\prime}$ phases of Co-Al-Wbased and Ni-Al-based superalloys. For the $\gamma$ phase, the simulation began with a single, isolated $A B$ dislocation. Once introduced, it immediately dissociated according to the following reaction.

$$
A B \rightarrow A \delta+\mathrm{ISF}+\delta B
$$

This dislocation dissociation is illustrated in Figure 7. The dislocation crystal free energy profiles are very similar, since the ISF energies of fcc-Co and fcc-Ni are close. The dislocation reaction shown above is also shown on the $\Gamma$-surface with the relevant dislocation labels using the Thomson tetrahedron notation.

A single, isolated $A B$ dislocation in the $\gamma^{\prime}$ phase would create an APB and so a $2 A B$ dislocation was introduced. This dislocation then dissociated according to the following reaction.

$$
2 A B \rightarrow A \delta+\mathrm{CSF}+\delta B+\mathrm{APB}+A \delta+\mathrm{CSF}+\delta B
$$

Figure 8 shows the crystal free energy of the relaxed state of the dislocation cores in $\mathrm{Ni}_{3} \mathrm{Al}$ and $\mathrm{Co}_{3}(\mathrm{Al}, \mathrm{W})$. The crystal free energy plot shows that the dislocations in $\mathrm{Ni}_{3} \mathrm{Al}$ have been able to relax to a wider configuration. This is mainly due to the significantly lower APB and CSF energies.

For both the $\gamma$ and $\gamma^{\prime}$ phases, the Co-based superalloy has more constricted dislocations due to the higher SISF and APB energies. This means that a larger number of dislocations can occupy the same slip plane in a Co-based superalloy. More constricted dislocations also mean 
cross-slip onto other planes occurs more easily [55], which can potentially improve anomalous yield behaviour.

The line energy of the dislocations in the Co-based and Ni-based superalloys can also be considered in the PFMD. By integrating the crystal free energy curves shown in Figures 7 and 8 the line energy of each dislocation can be calculated. In fcc-Co and fcc-Ni, the line energies of dislocations in their relaxed state are $0.47 \mathrm{~J} / \mathrm{m}$ and $0.36 \mathrm{~J} / \mathrm{m}$, respectively. For the $\gamma^{\prime}$ phase, the line energies in $\mathrm{L}_{2}-\mathrm{Co}_{3}(\mathrm{Al}, \mathrm{W})$ and $\mathrm{L1}_{2}-\mathrm{Ni}_{3} \mathrm{Al}$ are $1.5 \mathrm{~J} / \mathrm{m}$ and $1.0 \mathrm{~J} / \mathrm{m}$ respectively. The line energies in Co-based alloys are approximately $30 \%$ greater than that of Ni-based superalloys. Larger line energies make it more difficult for dislocations to bow around precipitates. Therefore, if a dislocation encounters a precipitate that it is difficult shear, the higher line energy dislocation would bow less and hence enhance the strengthening of the material.

\subsection{Binary $\mathrm{LI}_{2}$ compounds}

$\Gamma$-surfaces for $16 \mathrm{Ll}_{2}\left(\mathrm{~A}_{3} \mathrm{~B}\right)$ systems were calculated with $A$ : $\mathrm{Ni}, \mathrm{Co}$ and $B: \mathrm{Al}, \mathrm{Ti}, \mathrm{V}, \mathrm{Cr}$, $\mathrm{Nb}, \mathrm{Mo}, \mathrm{Ta}, \mathrm{W}, \mathrm{Ni}, \mathrm{Co}$. The $B$-type atoms were chosen since they are found to partition to the $\gamma^{\prime}$-phase in $\mathrm{Ni} / \mathrm{Co}$-based superalloys. Additionally, calculations for $\mathrm{Ni}_{3} \mathrm{Co}$ and $\mathrm{Co}_{3} \mathrm{Ni}$ were used to investigate the anti-site occupation in both Co-based and Ni-based binary alloys.

One-dimensional profiles of the $\Gamma$-surfaces along the [ $\overline{1} \overline{1} 2]$ and [ $\overline{1} 10]$ directions are shown in Figure 9 and the energy values of the minima are given in Table 8 . The majority of the $\mathrm{Co}_{3} \mathrm{X}$ and $\mathrm{Ni}_{3} \mathrm{X}$ profiles display the same general topography which is expected since the same twodimensional Fourier series are fitted. A much greater proportion of the $\mathrm{Ni}_{3} \mathrm{X}$ profiles take on negative values, implying that the $\mathrm{L}_{2}$ structure is not preferred in most configurations. This also implies that the presence of Co atoms on the face centre sites tends to stabilise the $\mathrm{L}_{2}$ structure.

In most of the profiles, three minima are found at $y \approx \frac{1}{6}, y \approx \frac{1}{2}$ and $y=\frac{2}{3}$, which correspond to the energies of the complex stacking fault (CSF), anti-phase boundary (APB) and superlattice intrinsic stacking fault (SISF) respectively. Yamaguchi et al. [56] studied the expected positions of planar faults in $\mathrm{L}_{2}$ crystals by calculating the $\Gamma$-surface using central force potentials in a hard-sphere model (HSM). Using symmetry arguments, the authors showed that the SISF would always be stable and would always occur at the position predicted by the HSM. On the other hand, the APB and CSF need not be stable and their respective positions on the $\Gamma$-surface can deviate from the positions predicted by the HSM along given directions. As such, the minima that correspond to SISFs are consistent in their positions, while the minima positions that correspond to either CSFs or APBs are inconsistent as can be seen in Figure 9 .

Table 9 shows some fault energy values from literature, but is sparse except for $\mathrm{Ni}_{3} \mathrm{Al}$, which has been extensively studied. The fault energies calculated by Schoeck et al. [30] used a six layer tilted supercell. Only relaxation of the atoms in the planes that encompassed the fault was allowed. This, along with the larger cell used for the present work, could explain why the values of Shoeck et al. are consistently higher than those of the present study.

There have also been studies to investigate the energetics of APBs in Co-Al-W superalloys. Saal and Wolverton [49] measured the APB energies of $\mathrm{Co}_{3} \mathrm{Al}$ and $\mathrm{Co}_{3} \mathrm{~W}$ to be $-14 \mathrm{~mJ} / \mathrm{m}^{-2}$ and $399 \mathrm{~mJ} / \mathrm{m}^{-2}$, respectively. The APB energy calculated in the present work for $\mathrm{Co}_{3} \mathrm{Al}$ was -135 $\mathrm{mJ} / \mathrm{m}^{-2}$ and for $\mathrm{Co}_{3} \mathrm{~W}$ was $485 \mathrm{~mJ} / \mathrm{m}^{-2}$. The fault energies from Saal et al. were calculated with a six layer tilted supercell and both the positions of the atoms and the length of cell vector were optimised. Additionally, the calculations were spin-polarised, which may explain the significant difference between the APB energies for both $\mathrm{Co}_{3} \mathrm{Al}$ and $\mathrm{Co}_{3} \mathrm{~W}$ when compared with the present findings. 
The fault energies of the various intermetallic compounds can be compared in Figure 10 . where they are plotted against the lattice parameter. The lattice parameter for each $\mathrm{L}_{2}$ compound was determined by computing energy volume curves. The curves were fitted to a continuous function based on the Birch-Murnaghan equation of state [57]. The equilibrium volume that corresponds to the minimum energy was then used to calculate a lattice parameter.

The blue and black points in Figure 10 correspond to the Co-based and Ni-based $\mathrm{L}_{2}$ systems respectively. There are clear similarities between the variation of APB and CSF energy values. This is expected, since both faults cause the same changes in the bonding environment up until the second nearest neighbour [48]. For the Co-based systems, the APB and CSF energies tend to increase with lattice parameter. This trend can imply that the Co-based large lattice parameter systems are more stable in their $\mathrm{L1}_{2}$ crystals. In general, the opposite trend can be seen in the Ni-based systems for APB and CSF energies.

The SISF energy of $\mathrm{Co}_{3} \mathrm{Ti}$ is the highest $\left(239 \mathrm{~mJ} / \mathrm{m}^{-2}\right)$ among all the binary compounds studied in this work. Titus et al. [54] studied primary creep in multiple Co-based and CoNibased single crystal superalloys. Interestingly, the authors found that the Co-based alloy with the largest fraction of $\mathrm{Ti}$ exhibited the lowest number of stacking faults, which indicates that the presence of Ti may increase the SISF energy. However, the authors also mentioned that the increased creep resistance shown by the Ti containing alloy could be due to the tendency of $\mathrm{Ti}$ to increase $\gamma^{\prime}$ volume fraction and phase stability [58]. Nevertheless, the SISF energy must also play a role in the performance of the Ti-containing Co-based alloys during primary creep.

The fault energies of the pairs 1) Ta \& Nb and 2) W \& Mo lie close to one another for SISF, $\mathrm{APB}$ and CSF energy. For instance, the APB energies of $\mathrm{Co}_{3} \mathrm{Ta}$ and $\mathrm{Co}_{3} \mathrm{Nb}$ are very similar. This also applies to the APB energies of $\mathrm{Ni}_{3} \mathrm{Ta}$ and $\mathrm{Ni}_{3} \mathrm{Nb}$. The atoms in both pairs are in the same group in the periodic table and have similar atomic radii. The similarity in planar fault energy implies that, for alloys containing these pairs of elements, segregation to reduce fault energy may not occur.

\subsection{DFT vs. experimental observations}

Using other fault energy trends, one can begin to predict segregation pathways of atoms during and after formation of stacking faults. For instance, Viswanathan et al. [59], investigated segregation at superlattice intrinsic stacking faults in two commercial superalloys, CMSX-4 and alloy ME3. In both Ni-based superalloys the authors found that $\mathrm{Cr}$ and $\mathrm{Al}$ would segregate towards and away from the SISF respectively. Figure 10 not only shows that the SISF energy of $\mathrm{Ni}_{3} \mathrm{Cr}$ is lower relative to that of $\mathrm{Ni}_{3} \mathrm{Al}$ but also that $\mathrm{Ni}_{3} \mathrm{Cr}$ exhibits a negative SISF energy.Thus, there is apparent agreement between the DFT data and the experimental observations of Viswanathan et al.

Eggeler et al. [60] also investigated segregation at two types of fault in a CoNi-based superalloy. Both faults, the SISF and APB, were enriched in $\mathrm{Cr}$ and $\mathrm{Co}$, whilst being depleted of Al. The enrichment in $\mathrm{Cr}$ at the APB is in agreement with the negative APB energies calculated for $\mathrm{Ni}_{3} \mathrm{Cr}$ and $\mathrm{Co}_{3} \mathrm{Cr}$. However, the observation of significant enrichment in Co within both faults and a depletion of $\mathrm{Ni}$ is surprising, since $\mathrm{Ni}_{3} \mathrm{X}$ SISF and APB energies tend to be lower than the $\mathrm{Co}_{3} \mathrm{X}$ energies. Nevertheless, this study assumes that the Co and $\mathrm{Ni}$ atoms solely occupy the $\mathrm{A}$ site of the $A_{3} B$ crystals and hence, the discussion of segregation is limited to the diffusion of solutes to and from the $B$ sub-lattice sites. Consistent with these observations, a subsequent study by Lenz et al. [61] also found that Co and $\mathrm{Cr}$ segregated to planar faults in another CoNi-based single crystal superalloy. 
Figure 10 also shows the planar fault energies of $\mathrm{Co}_{3} \mathrm{Ni}$ and $\mathrm{Ni}_{3} \mathrm{Co}$ with values of 75:-84:128 $\mathrm{mJ} / \mathrm{m}^{2}$ and 122:-28:143 mJ/m², respectively (CSF:APB:SISF). The planar fault energies for these systems were calculated to understand the effect of incorrect site occupation in both $\mathrm{Co}$ and $\mathrm{Ni}$ based superalloys. Meher et al. [62] showed that within quaternary alloys containing both Co and $\mathrm{Ni}$, the $\mathrm{Al} / \mathrm{W}$ site in the $\gamma^{\prime}$ phase is shared with $\mathrm{Ni}$ atoms. Since Eggeler et al. showed Ni depletion at a SISF fault, one would expect the SISF energy of $\mathrm{Co}_{3} \mathrm{Ni}$ to be higher than that of $\mathrm{Co}_{3}(\mathrm{Al}, \mathrm{W})$, which is not the case for the DFT data, as can be seen from Figure 10

Titus et al. [63] also studied solute segregation around SISF faults. The authors were studying Co-based alloys that contained Al, W, Ta, Ti and Cr. In nickel-free Co-Al-W-based alloys, it was found that the elements with larger atomic radii, $\mathrm{W}$ and $\mathrm{Ta}$, tend to segregate towards the SISF region and the smaller elements, $\mathrm{Al}$ and $\mathrm{Cr}$, would diffuse away from the SISF region. This is an interesting observation when compared to Figure 10 , since $\mathrm{Co}_{3} \mathrm{Cr}$ has the lowest SISF energy of all the binary $\mathrm{Co}_{3} \mathrm{X}$ compounds, which is negative. The $\mathrm{Co}_{3} \mathrm{Al}$ SISF energy is also negative. At the same time, $\mathrm{Co}_{3}$ Ta has a greater SISF energy than the $\mathrm{Co}_{3}(\mathrm{Al}, \mathrm{W})$. This suggests either that some of these elements segregate to the A sub-lattice and/or the relaxation of local misfit strain around the SISF is more energetically favourable than further reduction in fault energy.

The partitioning of $\mathrm{W}$ to the SISF region is interesting since this process is similar to the formation of the $\mathrm{DO}_{19}-\mathrm{Co}_{3} \mathrm{~W}$ phase which is in thermodynamic equilibrium with the $\gamma^{\prime}-\mathrm{L} 1_{2}$ phase in the ternary $\mathrm{Co}-\mathrm{Al}-\mathrm{W}$ system $[65]$. The $\mathrm{DO}_{19}-\mathrm{Co}_{3} \mathrm{~W}$ phase is considered undesirable since it reduces the volume fraction of the $\gamma^{\prime}$ phase, thereby reducing the precipitate strengthening effect in the Co-based superalloys [66]. A more detailed study by Titus et al. [64] combining experimental and first principles techniques has shown that the composition of an SISF should not actually reach the $\mathrm{Co}_{3} \mathrm{~W}$ stoichiometry, as there is an interplay between the bulk thermodynamics and the competing interfacial energy. Thus the $\mathrm{W}$ concentration lies between the bulk D0 $0_{1} 9$ and $\mathrm{L}_{2}$ compositions (around Co-11Al-14W [at.\%]).

A recent DFT study by Rao et al. [72] has investigated the segregation of alloying elements to planar faults in $\mathrm{Ni}_{3} \mathrm{Al}$. A range of planar faults was created using these cells, including SISF, APB and CSF. The authors then substituted in a single solute atom ( $\mathrm{Co}, \mathrm{Cr}, \mathrm{Nb}$ or $\mathrm{Ta}$ ) into the plane of the fault and, in turn, into each of the five adjacent $\{111\}$ layers (i.e. at a progressively increasing distance from the fault layer). Substitution on both $\mathrm{Ni}$ and $\mathrm{Al}$ sub-lattice sites was investigated. An interaction energy was then calculated to evaluate the driving force for solute segregation, which was a difference of the stacking fault energies with and without the solute atom.

For $\mathrm{Al}$ site substitution, only the segregation of Co to APBs was found to result in a negative interaction energy (i.e. a positive driving force). This is consistent with the present our study. In For Ni site substitution, negative interaction energies were obtained for the following cases: (i) $\mathrm{Cr}$ in SISF; (ii) $\mathrm{Co}, \mathrm{Cr}$ and $\mathrm{Ta}$ in $\mathrm{APB}$; (iii) $\mathrm{Co}, \mathrm{Cr}$ and $\mathrm{Ta}$ in CSF. Interestingly, the authors found that in many cases solute atom substitution to $\{111\}$ adjacent to the fault resulted in a positive interaction energy and hence a negative driving force. This would imply that the diffusion of a solute atom towards the fault layer would be unfavourable even if there was an ultimate lowerenergy state when it reached the fault. The authors concluded that their simulations showed no obvious driving force for solute segregation to planar faults. Since this is contrary to numerous experimental observations, it was rationalised that metastable precursor structures must be involved, which are attractive to solutes.

One of the limitations of the study by Rao et al. may be that the solute concentration is quite low, i.e. 1 out 92 atoms, or 0.52 at.\%. Typically, the solute elements investigated are present within the $\gamma^{\prime}$ phase in concentrations that are at least an order of magnitude larger. Thus, the 
driving force is likely to be different. To take this into account, one may consider the average $\mathrm{L}_{2}$ lattice properties for a given composition. Table 10 presents an application of simple Vegardtype law of mixtures using the binary compound fault energies to experimental measurements of solute segregation to/from the corresponding faults (SISFs and APBs).

Two schemes are employed for averaging the $\mathrm{Ni}_{3} \mathrm{X}$ and $\mathrm{Co}_{3} \mathrm{X}$ fault energies using proportional contributions based on the experimentally measured compositions. The mathematical descriptions are provided in the supplementary information. Both schemes take into account $\mathrm{Ni}_{3} \mathrm{Co}$ and $\mathrm{Co}_{3} \mathrm{Ni}$ anti-site occupation, while Scheme 2 also takes into account $\mathrm{Ni}_{3} \mathrm{Ni}$ and $\mathrm{Co}_{3} \mathrm{Co}$ (i.e. pure fcc) contributions. Another key assumption of both methods is that A sites of the $\mathrm{A}_{3} \mathrm{~B}$ crystal lattice can only be occupied by either Ni or Co atoms. Thus, $\Gamma_{\text {fault }}$ and $\Gamma_{\text {precip. }}$ present estimates of the fault energy for the fault and surrounding crystal compositions respectively, while $\delta_{\Gamma}=\Gamma_{\text {fault }}-\Gamma_{\text {precip. }}$.

It can be seen that, in all but one case (SISF in ME3), a negative $\delta_{\Gamma}$ is obtained. For the single exception, $\delta_{\Gamma}$ is still negative when Scheme 2 is used, while $\delta_{\Gamma}$ is negative when the $\mathrm{Ni}_{3} \mathrm{X}$ and $\mathrm{Co}_{3} \mathrm{X}$ contributions are considered individually ( -14 and $-15 \mathrm{~mJ} / \mathrm{m}^{2}$ respectively), but the altered Ni:Co ratio gives a positive result. Therefore, the averaged crystal estimates largely predict a positive driving force for the experimentally measured solute segregation. This offers new perspective avenues for multi-scale modelling of multi-component alloys using ab-initio data and , specifically, may allow a more complete description of high-temperature deformation in superalloys.

However, one must be cautions and ensure that the averaging scheme is physically meaningful and rigorous. For SISFs, Scheme 2 gives positive fault energies, which is not the case for Scheme 1 where the fault energies are only positive for CoNi alloys. For the APBs, all predicted fault energies are negative. A negative fault energy would presume the growth of the fault and hence Scheme 2 seems more accurate for SISF. Neither method seems appropriate for APB energy estimation, and it is likely that a greater range of inter-atomic interactions needs to be included. We shall examine this in a separate publication. Furthermore, experimental observations of solute segregation to/from APBs (and in some cases SISFs) suggest that the phenomenon can destroy the chemical ordering within the fault (i.e. localised conversion to the $\gamma$ phase), while the data in Table 10 assume that order is maintained. Nonetheless, consistently negative $\delta_{\Gamma}$ values obtained for all the experimental data warrant further investigation of this subject.

The segregation of solutes near planar faults can have either positive or negative implications for the strengthening of superalloys. If, as a result of segregation in the $\mathrm{L}_{2}$ phase, the order of the precipitate is maintained, then a more stable region is formed, which can help in the strengthening of the material. However, chemical order in a fault region can be destroyed as a result of segregation too. For instance, Eggeler et al. [60] found that the APB regions of a CoNibased superalloy approached the structure and composition of the $\gamma$ phase as a result of solute diffusion. This eventually leads to the segmentation and disintegration of the $\gamma / \gamma^{\prime}$ microstructure and hence a negative effect on the strength of the superalloy. Lenz et al. [61] also observed a microstructural instability in a creep-deformed Co-based single crystal alloy which exhibited the formation of $\gamma$ nano-precipitates within $\gamma^{\prime}$ at the intersections and kinks of the numerous planar faults. Finally, one must also consider the effect on the misfit near planar faults and its subsequent effect on coherency and work/forest hardening. The relaxation of misfit strains resulting from Suzuki segregation effects may negate these beneficial strengthening effects. 


\section{Conclusions}

Generalised stacking fault energy surfaces have been calculated for a range of Ni-based and Co-based compounds, using a method that includes the explicit relaxation of both atomic positions as well as cell volume. A special quasirandom structure was employed for the $\Gamma$-surface calculation of $\mathrm{L}_{2}-\mathrm{Co}_{3}(\mathrm{Al}, \mathrm{W})$ and the subsequent planar fault energies were found to be significantly dependent on both local composition and configuration of the $\mathrm{Al} / \mathrm{W}$ atoms. The planar fault energies were generally found to be in agreement with values from literature. However, the more robust relaxation method did tend to agree more with studies that implemented larger cells. This implies that the calculation method presented here, provides a robust platform from which PFMD can benefit in simulating deformation mechanisms in superalloys.

As such, the PFMD was used compare the dislocation cores in both $\gamma$ and $\gamma^{\prime}$ phase of CoAl-W-based and Ni-Al-based superalloys. The higher planar fault energies in both phases for Co-Al-W-based superalloys caused a more constricted dislocation with a higher line energy.

The $\Gamma$-surfaces for various $\mathrm{Ni}$-based and Co-based $\mathrm{L}_{2}$ compounds were also calculated. The planar fault energies were compared to elucidate common solute segregation that has been observed in the planar faults of both Ni-based and Co-based superalloys. The relative values of the planar fault energies were generally successful in predicting the direction of solute segregation found via experiments.

The range of planar fault energies found for the $\mathrm{L1}_{2}-\mathrm{Co}_{3}(\mathrm{Al}, \mathrm{W})$ presents an opportunity to calculate the $\Gamma$ surface of off-stoichiometric $\mathrm{L}_{2}-\mathrm{Co}_{3}\left(\mathrm{Al}_{x}, \mathrm{~W}_{1-x}\right)$. Additionally, the novel $\Gamma$ surfaces of Co-Al-W-based superalloys can now be used in the PFMD to investigate the shear of the $\gamma^{\prime}$ precipitates in a range of microstructures by different types of dislocations. This will aid in the development of the next generation of Co-Al-W-based superalloys.

\section{Acknowledgements}

$\mathrm{HH}$ would like to gratefully acknowledge funding from the EPSRC Centre for Doctoral Training on Theory and Simulation of Materials at Imperial College London under grant number EP/L015579/1. VAV would like to acknowledge support from Rolls-Royce plc and Imperial College London under the Imperial College Research Fellowship scheme. Calculations were performed at the Imperial College Research Computing Service, doi:10.14469/hpc/2232. 
Tables

\begin{tabular}{lccccccc} 
& $\bar{\Pi}_{2,(1-3)}$ & $\bar{\Pi}_{2,4}$ & $\bar{\Pi}_{2,(5-6)}$ & $\bar{\Pi}_{3,(1-3)}$ & $\bar{\Pi}_{4,1}$ & $\bar{\Pi}_{4,2}$ & $\bar{\Pi}_{4,3}$ \\
\hline Random & 0 & 0 & 0 & 0 & 0 & 0 & 0 \\
SQS & 0 & -0.33 & 0 & 0 & -0.11 & 0 & 0.33 \\
\hline
\end{tabular}

Table 1: Correlation function of the SQS used for the $\mathrm{L}_{2}$ crystal of $\mathrm{Co}_{3}(\mathrm{Al}, \mathrm{W})$.

\begin{tabular}{lcccc}
\hline & \multicolumn{4}{c}{ Number of Layers } \\
\cline { 2 - 5 } & 6 & 9 & 12 & 15 \\
\hline$\Gamma_{\mathrm{ISF}}$ & 149 & 153 & 152 & 154 \\
$\Gamma_{\mathrm{USF}_{2}}$ & 1087 & 1091 & 1095 & 1096 \\
\hline
\end{tabular}

Table 2: Intrinsic stacking fault (ISF) and unstable stacking fault $\left(\mathrm{USF}_{2}\right)$ energies $\left(\mathrm{mJ} / \mathrm{m}^{2}\right)$ of fcc Ni using supercells of increasing size, with 4 atoms per layer.

\begin{tabular}{lcc}
\hline System & \multicolumn{2}{c}{ Energy Difference } \\
& $\mathrm{meV} /$ atom & $\mathrm{mJ} / \mathrm{m}^{2}$ \\
\hline $\mathrm{Co}_{3} \mathrm{Al}$ & -0.20 & -0.52 \\
$\mathrm{Ni}_{3} \mathrm{Al}$ & 0.11 & 0.29 \\
\hline
\end{tabular}

Table 3: The energy difference due to inequivalent $k$-point sampling is shown between perfect crystals with and without the $a_{3}$ cell vector being tilted in the direction $a[\overline{2} 11]$. 


\begin{tabular}{lcccc}
\hline & $\mathrm{Co}$ & $\mathrm{Ni}$ & $\mathrm{Co}_{3}(\mathrm{Al}, \mathrm{W})$ & $\mathrm{Ni}_{3} \mathrm{Al}$ \\
\hline $\mathrm{c}_{11}(\mathrm{GPa})$ & 297 & 276 & 264 & 224 \\
$\mathrm{c}_{12}(\mathrm{GPa})$ & 172 & 160 & 162 & 148 \\
$\mathrm{c}_{44}(\mathrm{GPa})$ & 144 & 126 & 153 & 125 \\
Lattice parameter $(\AA)$ & 3.46 & 3.51 & 3.57 & 3.57 \\
\hline
\end{tabular}

Table 4: The various properties of each material used in the PFMD is shown. The lattice parameters were calculated by fitting the Birch-Murnaghan equation of state to energy volume curves [67, 57] produced in CASTEP. The elastic constants of Ni and Co were obtained from DFT calculations by Shang et al. [68]. The elastic constants for $\mathrm{Ni}_{3} \mathrm{Al}$ were obtained from Kayser and Stassis ultrasound measurements [69]. The $\mathrm{Co}_{3}(\mathrm{Al}, \mathrm{W})$ elastic constants were obtained from DFT calculations by Jiang [70].

\begin{tabular}{lccccccc}
\hline & \multicolumn{3}{c}{$\Gamma_{\text {ISF }}$} & & $\Gamma_{\text {USF }_{1}}$ & No. of (111) \\
& $\mathrm{Ni}$ & $\mathrm{Co}$ & $\mathrm{Al}$ & $\mathrm{Ni}$ & $\mathrm{Co}$ & $\mathrm{Al}$ & Planes \\
\hline Present work & 153 & 163 & 122 & 275 & 455 & 159 & 9 \\
Rosengaard \& Skriver [41] & 181 & 195 & - & - & - & - & 8 \\
Zimmerman et al. [40] & 183 & - & - & 350 & - & - & 6 \\
Siegel [71] & $\mathbf{1 1 0}$ & - & - & $\mathbf{2 7 3}$ & - & - & 10 \\
Hunter et al. [16] & 145 & - & - & - & - & - & 16 \\
Brandl et al. [15] & $\mathbf{1 3 7}$ & - & - & $\mathbf{2 7 8}$ & - & - & 12 \\
Chandran \& Sondhi [39] & 159 & - & - & - & - & - & 14 \\
& $\mathbf{1 2 7}$ & - & - & - & - & - & 14 \\
Woordward et al. [42] & - & - & 124 & - & - & - & - \\
Lu et al. [43] & - & - & 164 & - & - & 400 & 9 \\
\hline
\end{tabular}

Table 5: Calculated values of fault energies $\left(\mathrm{mJ} / \mathrm{m}^{2}\right)$ in fcc Ni and Co crystals. The number of $\{111\}$ layers used in the supercells is also shown. The numbers in bold were obtained using spin-polarised calculations.

\begin{tabular}{lccccc}
\hline & \multicolumn{3}{c}{ Co } & \multicolumn{3}{c}{$\mathrm{Ni}$} \\
\hline Magnetic moment $\left(\mu_{B} /\right.$ atom $)$ & - & - & 1.67 & - & 0.66 \\
Lattice parameter $(\AA)$ & 3.46 & 3.53 & 3.53 & 3.51 & 3.52 \\
$\Gamma_{\mathrm{ISF}}\left(\mathrm{mJ} / \mathrm{m}^{2}\right)$ & 166 & 154 & -100 & 157 & 154 \\
$\Gamma_{\mathrm{USF}}\left(\mathrm{mJ} / \mathrm{m}^{2}\right)$ & 500 & 325 & 277 & 290 & 325 \\
\hline
\end{tabular}

Table 6: Results of spin polarised calculations for fcc-Ni and fcc-Co. 


\begin{tabular}{|c|c|c|c|c|c|c|}
\hline & & $\begin{array}{l}\text { Present } \\
\text { Work }\end{array}$ & $\begin{array}{c}\text { Present } \\
\text { Work } \\
\text { S-P }\end{array}$ & $\begin{array}{c}\text { Vamsi and } \\
\text { Karthikeyan } \\
{[51]}\end{array}$ & $\begin{array}{c}\text { Saal and } \\
\text { Wolverton } \\
\text { [49] }\end{array}$ & $\begin{array}{c}\text { Mottura } \\
\text { et al. } \\
{[50]}\end{array}$ \\
\hline \multirow{4}{*}{$\mathrm{Co}_{3}(\mathrm{Al}, \mathrm{W})$} & $\Gamma_{\mathrm{SISF}}$ & $167 \pm 70$ & $176 \pm 61$ & 87 & - & $89-93$ \\
\hline & $\Gamma_{\mathrm{APB}}$ & $425 \pm 123$ & $397 \pm 128$ & 293 & 261 & - \\
\hline & $\Gamma_{\mathrm{CSF}}$ & $388 \pm 150$ & $369 \pm 155$ & 287 & - & - \\
\hline & & $\begin{array}{c}\text { Present } \\
\text { Work }\end{array}$ & $\begin{array}{c}\text { Vamsi and } \\
\text { Karthikeyan } \\
448\end{array}$ & $\begin{array}{c}\text { Mryasov } \\
\text { et al. } \\
{[46}\end{array}$ & $\begin{array}{c}\text { Schoeck } \\
\text { et al. } \\
{[47}\end{array}$ & $\begin{array}{l}\text { Rao } \\
\text { et al. } \\
{[72]} \\
\end{array}$ \\
\hline \multirow{3}{*}{$\mathrm{Ni}_{3} \mathrm{Al}$} & $\Gamma_{\mathrm{SISF}}$ & 74 & 39 & 80 & 79 & 37 \\
\hline & $\Gamma_{\mathrm{APB}}$ & 162 & 152 & 210 & 220 & 172 \\
\hline & $\Gamma_{\mathrm{CSF}}$ & 191 & 170 & 225 & 267 & 187 \\
\hline
\end{tabular}

Table 7: Most recent calculations of fault energies $\left(\mathrm{mJ} / \mathrm{m}^{2}\right)$ in both $\mathrm{Co}_{3}\left(\mathrm{Al}_{0.5}, \mathrm{~W}_{0.5}\right)$ and $\mathrm{Ni}_{3} \mathrm{Al}$. The fault energies in the present work for $\mathrm{Co}_{3}(\mathrm{Al}, \mathrm{W})$ are taken as averages of the fault energies of the three chosen fault planes in the SQS. The numbers in bold were obtained using spin-polarised calculations. 


\begin{tabular}{|c|c|c|c|c|}
\hline \multirow[t]{2}{*}{ Crystal } & \multirow{2}{*}{$\begin{array}{l}\text { Lattice parameter } \\
a(\AA)\end{array}$} & \multicolumn{3}{|c|}{ Planar fault energy $\left(\mathrm{mJ} / \mathrm{m}^{2}\right)$} \\
\hline & & CSF & APB & SISF \\
\hline $\mathrm{Co}_{3} \mathrm{Ni}$ & 3.471 & 75 & -84 & 128 \\
\hline \multirow{3}{*}{$\mathrm{Co}_{3} \mathrm{Al}$} & 3.536 & -184 & -135 & -90 \\
\hline & $3.574[73]$ & $-65[51]$ & -14 [49] & $-151[51]$ \\
\hline & $3.658(\mathrm{E})[74$ & 560 [13] & $120[13]$ & $-95[13]$ \\
\hline \multirow[t]{3}{*}{$\mathrm{Co}_{3} \mathrm{Ti}$} & 3.575 & 245 & 367 & 239 \\
\hline & $\mathbf{3 . 6 0 1}[73]$ & & & \\
\hline & 3.572 [75] & & & 208 [75] \\
\hline \multirow[t]{3}{*}{$\mathrm{Co}_{3} \mathrm{~V}$} & 3.512 & 386 & 470 & -18 \\
\hline & $3.514[73$ & & & \\
\hline & $3.506[75]$ & & & \\
\hline \multirow[t]{2}{*}{$\mathrm{Co}_{3} \mathrm{Cr}$} & 3.479 & 8 & -13 & -259 \\
\hline & $3.476[75]$ & & & \\
\hline \multirow[t]{2}{*}{$\mathrm{Co}_{3} \mathrm{Nb}$} & 3.635 & 691 & 747 & 95 \\
\hline & $3.629[75]$ & & & \\
\hline \multirow[t]{2}{*}{$\mathrm{Co}_{3} \mathrm{Mo}$} & 3.587 & 474 & 362 & -276 \\
\hline & $3.59[75$ & & & \\
\hline \multirow[t]{4}{*}{$\mathrm{Co}_{3} \mathrm{Ta}$} & 3.637 & 761 & 803 & 199 \\
\hline & 3.637 [73] & & & \\
\hline & 3.64 (E) [76] & & & \\
\hline & $3.636[75]$ & & & \\
\hline \multirow[t]{3}{*}{$\mathrm{Co}_{3} \mathrm{~W}$} & 3.594 & 631 & 485 & -184 \\
\hline & 3.598 [73] & $523[51]$ & 399 [49] & $-252[51]$ \\
\hline & 3.595 [75] & 1190 [13] & 658 [13] & $-132[13]$ \\
\hline
\end{tabular}

Table 8: The calculated lattice parameter and planar fault energies for $\mathrm{Co}_{3} \mathrm{X} \mathrm{L1} 1_{2}$ crystals compared to literature values. The values determined by experiment are labelled by (E). The numbers in bold were obtained using spin-polarised calculations. 


\begin{tabular}{|c|c|c|c|c|}
\hline \multirow[t]{2}{*}{ Crystal } & \multirow{2}{*}{$\begin{array}{l}\text { Lattice parameter } \\
a(\AA)\end{array}$} & \multicolumn{3}{|c|}{ Planar fault energy $\left(\mathrm{mJ} / \mathrm{m}^{2}\right)$} \\
\hline & & CSF & APB & SISF \\
\hline $\mathrm{Ni}_{3} \mathrm{Co}$ & 3.501 & 122 & -28 & 143 \\
\hline \multirow{3}{*}{$\mathrm{Ni}_{3} \mathrm{Al}$} & 3.565 & 191 & 162 & 74 \\
\hline & $3.568[73]$ & 223 [47] & 172 [47] & 79 \\
\hline & $3.572(\mathrm{E})$ & $187[72]$ & 172 [72] & $37 \overline{72}$ \\
\hline \multirow[t]{2}{*}{$\mathrm{Ni}_{3} \mathrm{Ti}$} & 3.611 & 371 & 413 & -71 \\
\hline & $3.608[75]$ & & & \\
\hline \multirow[t]{2}{*}{$\mathrm{Ni}_{3} \mathrm{~V}$} & 3.561 & -512 & -612 & -663 \\
\hline & 3.557 [75] & & & \\
\hline \multirow[t]{2}{*}{$\mathrm{Ni}_{3} \mathrm{Cr}$} & 3.528 & -659 & -742 & -417 \\
\hline & $3.528[75]$ & & & \\
\hline \multirow[t]{2}{*}{$\mathrm{Ni}_{3} \mathrm{Nb}$} & 3.685 & -398 & -635 & -1060 \\
\hline & $3.685[75]$ & & & \\
\hline \multirow[t]{2}{*}{$\mathrm{Ni}_{3} \mathrm{Mo}$} & 3.637 & -748 & -908 & -782 \\
\hline & $3.645[75]$ & & & \\
\hline \multirow[t]{2}{*}{$\mathrm{Ni}_{3} \mathrm{Ta}$} & 3.685 & -319 & -635 & -1129 \\
\hline & 3.687 [75] & & & \\
\hline \multirow[t]{2}{*}{$\mathrm{Ni}_{3} \mathrm{~W}$} & 3.644 & -839 & -1130 & -988 \\
\hline & $3.648[75]$ & & & \\
\hline
\end{tabular}

Table 9: The calculated lattice parameter and planar fault energies for $\mathrm{Ni}_{3} \mathrm{X} \mathrm{L}_{2}$ crystals compared to literature values. The numbers in bold were obtained using spin-polarised calculations. 


\begin{tabular}{|cll|rrr|rrr|}
\hline \multirow{2}{*}{ Fault } & \multirow{2}{*}{ Alloy } & \multirow{2}{*}{ Base } & \multicolumn{3}{|c|}{ Scheme 1 } & \multicolumn{3}{|c|}{ Scheme 2 } \\
& & & $\Gamma_{\text {precip. }}$ & $\Gamma_{\text {fault }}$ & $\delta_{\Gamma}$ & $\Gamma_{\text {precip. }}$ & $\Gamma_{\text {fault }}$ & $\delta_{\Gamma}$ \\
\hline \multirow{5}{*}{ SISF } & {$[59]$ CMSX-4 } & $\mathrm{Ni}$ & -193 & -200 & -7 & 57 & 48 & -9 \\
& {$[59]$ ME3 } & $\mathrm{Ni}$ & -32 & -27 & 5 & 95 & 75 & -21 \\
& {$[78]$ LSHR } & $\mathrm{Ni}$ & -49 & -50 & -1 & 81 & 76 & -5 \\
& {$[79]$ CoAlW-2Ta } & $\mathrm{Co}$ & -104 & -112 & -7 & 89 & 81 & -8 \\
& {$[60]$ CoNi-A } & $\mathrm{CoNi}$ & 18 & 8 & -10 & 75 & 71 & -3 \\
& {$[80]$ ERBOCo-1 } & $\mathrm{CoNi}$ & 6 & 1 & -5 & 63 & 60 & -3 \\
\hline \multirow{2}{*}{ APB } & {$[81]$ MD2 } & $\mathrm{Ni}$ & -92 & -144 & -52 & -21 & -34 & -13 \\
& {$[60]$ CoNi-A } & $\mathrm{CoNi}$ & -69 & -72 & -3 & -43 & -48 & -4 \\
\hline
\end{tabular}

Table 10: Estimated fault energies (in $\mathrm{mJ} / \mathrm{m}^{2}$ ) calculated using Vegard-type law of mixtures averaging based on experimentally obtained compositions measured experimentally at faults $\left(\Gamma_{\text {fault }}\right)$ and in surrounding $\gamma^{\prime}$ crystal $\left(\Gamma_{\text {precip }}\right)$. The difference in energy $\delta_{\Gamma}$ is given by $\Gamma_{\text {fault }}-\Gamma_{\text {precip }}$. The averaging schemes and input data are presented in the supplementary information. 
Figures

a)
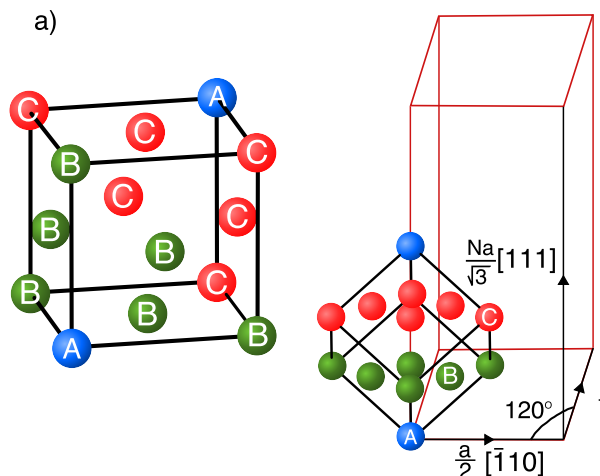

c)

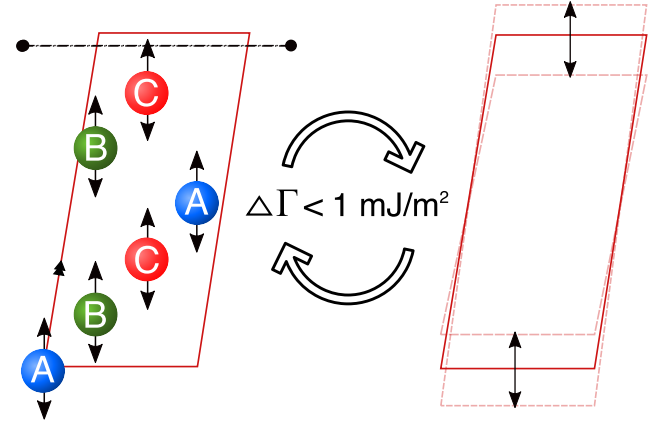

b)

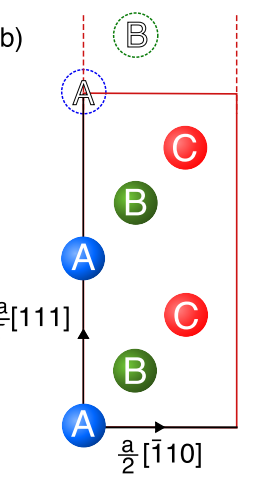

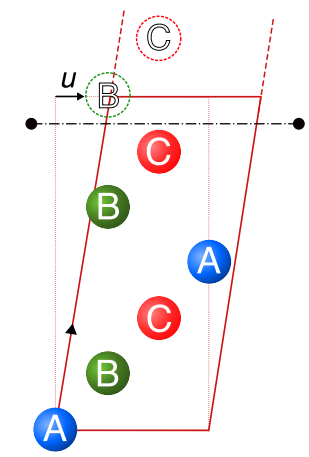

d)

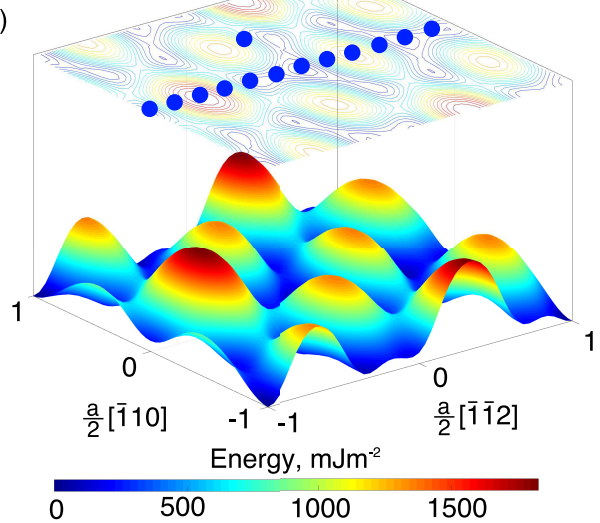

Figure 1: The details of the supercell and relaxation scheme used for the calculation of $\Gamma$-surfaces are shown. Figure (a) shows an fcc unit cell with three colours distinguishing between the 3 unique positions of the (111) planes. On the right, the unit cell is rotated such that a stack of (111) planes is created. The variable, $\mathrm{N}$, is the number of (111) planes and therefore $\mathrm{N}=6$. Figure (b) is a six layer supercell with a tilted cell on the right. Once the cell is titled by vector, $\mathbf{u}$, a planar fault is created at the top as well as the bottom of the cell (by the periodicity), shown by the black dashed line. The relaxation scheme is shown in Figure (c), where atomic positions were optimised first, followed by the optimisation of the [111] cell vector. This was iteratively repeated until the tolerance tests were satisfied ensuring a fully relaxed system. The (111) $\Gamma$ surface of $\mathrm{Ni}_{3} \mathrm{Al}$ is shown in panel (d) as a surface plot with a contour plot above. The points on the contour plot represent the displacement vectors for which the ab initio energy calculations were performed. 


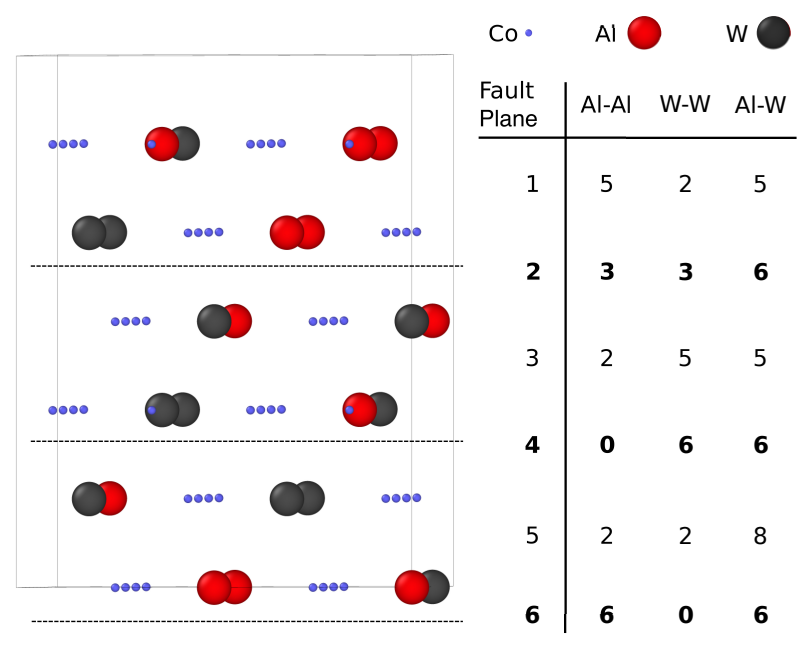

Figure 2: The SQS calculated using the ATAT package is shown as 6 (111) planes stacked on top of one another. There are six possible fault planes. Each fault plane can be characterised by counting the number of shortest Al-Al, W-W and Al-W bonds that intersect it. Fault planes 2,4 and 6 were chosen for the $\Gamma$-surface calculation since they include the range of interactions expected with this composition, $\mathrm{Co}_{3}\left(\mathrm{Al}_{0.5}, \mathrm{~W}_{0.5}\right)$.
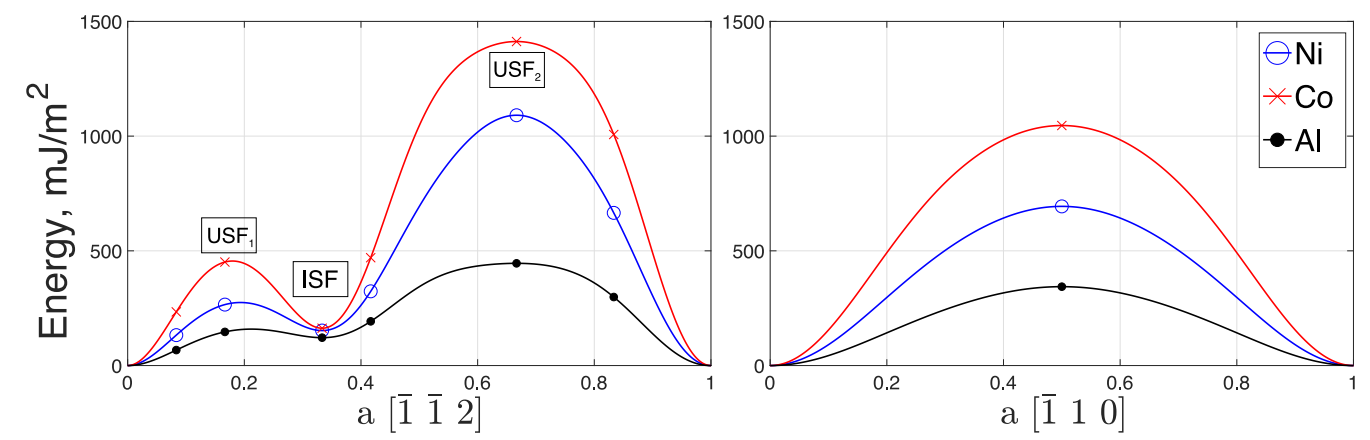

Figure 4: The $\Gamma$-surface profiles along the [ $\overline{1} \overline{1} 2]$ and [110] direction are shown for pure fcc Ni, $\mathrm{Co}$ and $\mathrm{Al}$ crystals. The points on the figure correspond to DFT calculations and the continuous lines are the 2D Fourier series fits. 


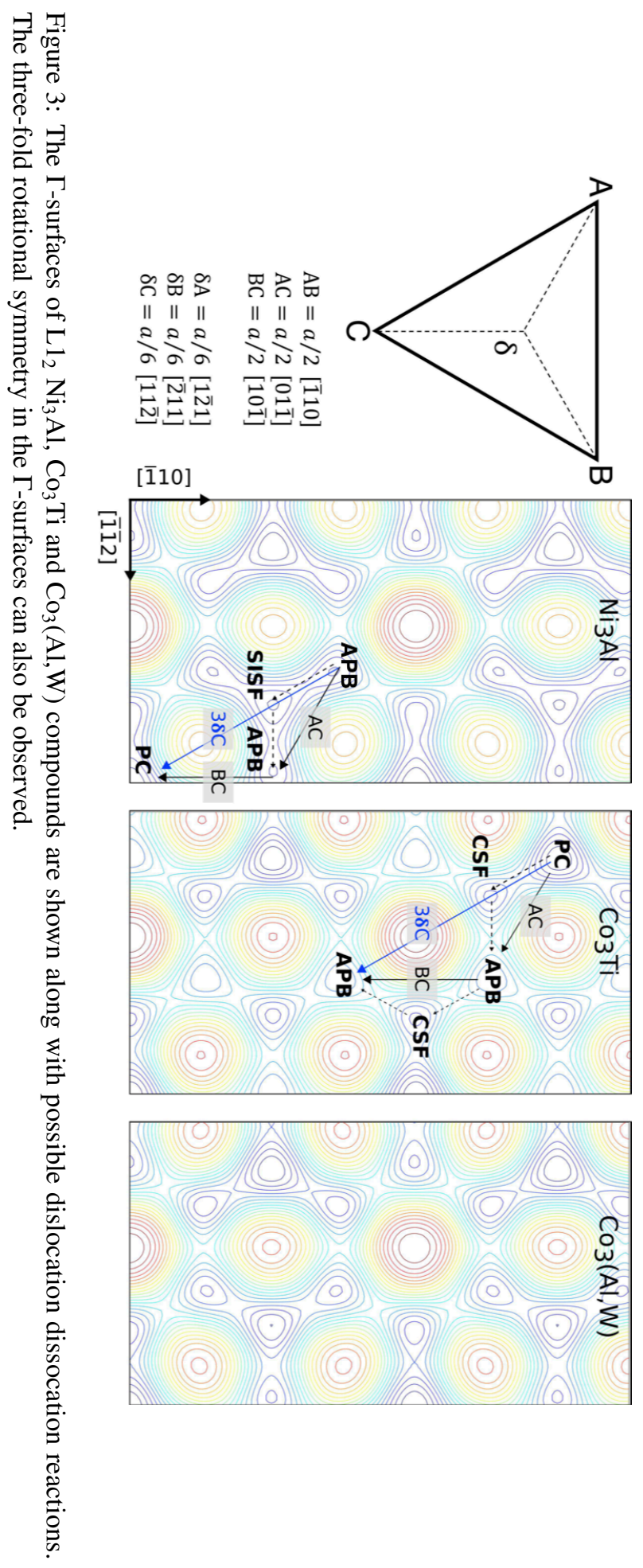




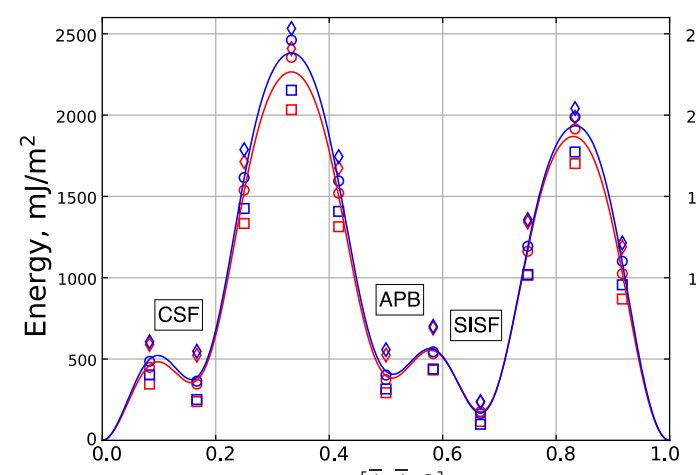

a $\left[\begin{array}{lll}\overline{1} & \overline{1} & 2\end{array}\right]$

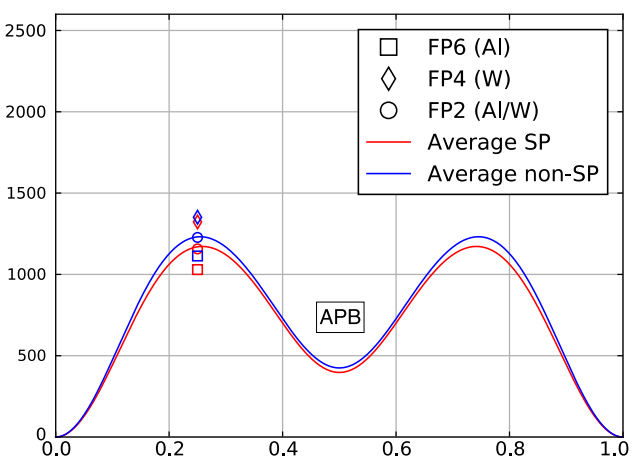

a $\left[\begin{array}{lll}1 & 1 & 0\end{array}\right]$

Figure 5: The $\Gamma$-surface profiles for the SQS of $\mathrm{Co}_{3}\left(\mathrm{Al}_{0.5}, \mathrm{~W}_{0.5}\right)$ are shown. The result of fault plane 2 (3:3:6 bond ratio) lies in between the results of fault planes 4 and 6 , as expected, with the average closely matching fault plane 2 at the local minima that correspond to planar faults.
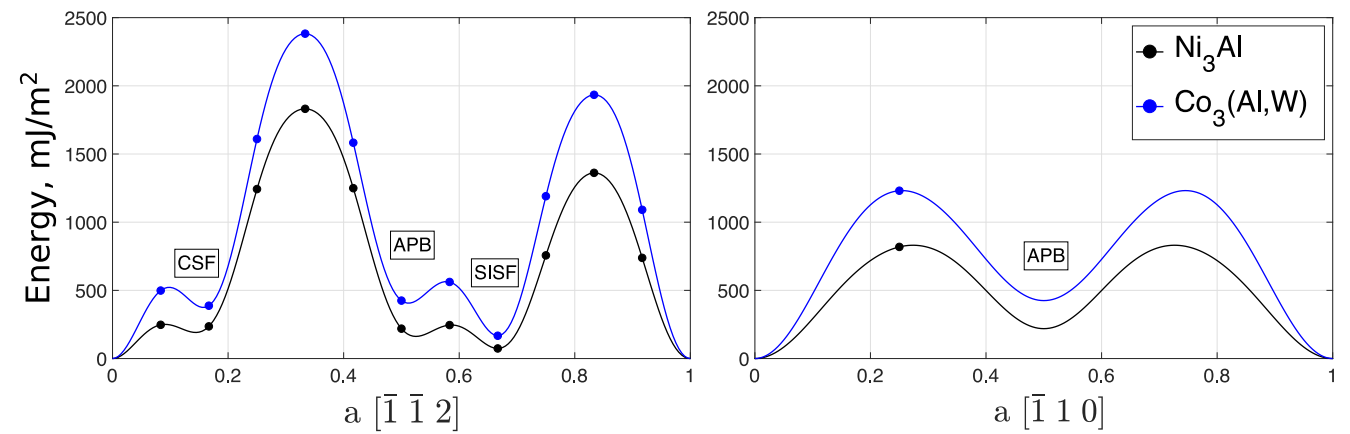

Figure 6: A direct comparison of $\mathrm{Ni}_{3} \mathrm{Al}$ and the averaged $\mathrm{Co}_{3}\left(\mathrm{Al}_{0.5}, \mathrm{~W}_{0.5}\right)$ is shown. As with the $\gamma$-phase calculations, the Co-based system has a consistently higher fault energy throughout the $\Gamma$-surface. 

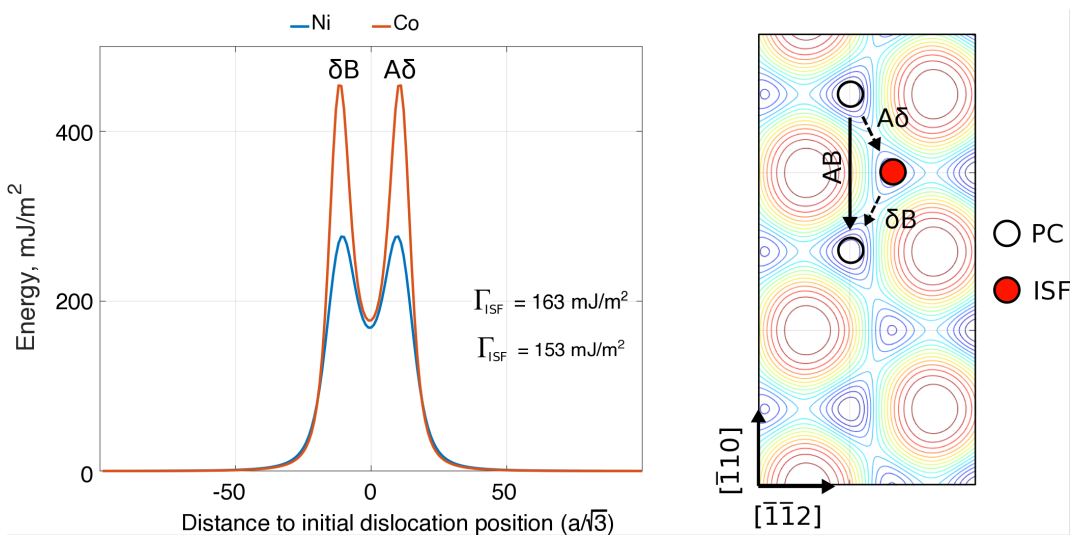

Figure 7: The fault energy profiles of a $2 \mathrm{BC}$ dislocation is compared for fcc $\mathrm{Ni}$ and $\mathrm{Co}$. As expected the $2 \mathrm{BC}$ dislocation undergoes a dislocation dissociation. This dissociation reaction is overlayed on the $\Gamma$-surface.
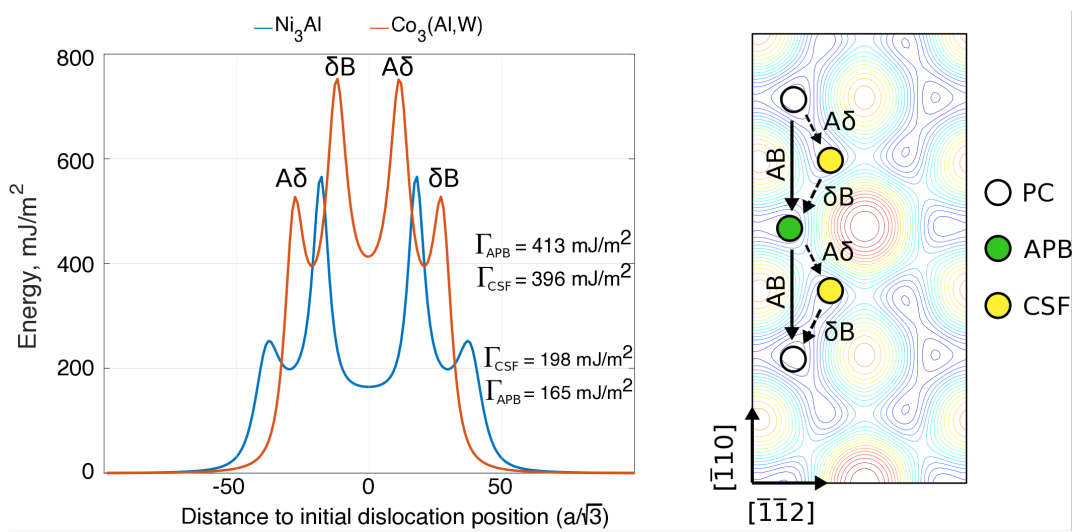

Figure 8: The fault energy profiles of a $2 \mathrm{BC}$ dislocation is compared for $\mathrm{Ni}_{3} \mathrm{Al}$ and $\mathrm{Co}_{3}(\mathrm{Al}, \mathrm{W})$. As expected the $2 \mathrm{BC}$ dislocation undergoes a dislocation dissociation. This dissociation reaction is overlayed on the $\Gamma$-surface. 

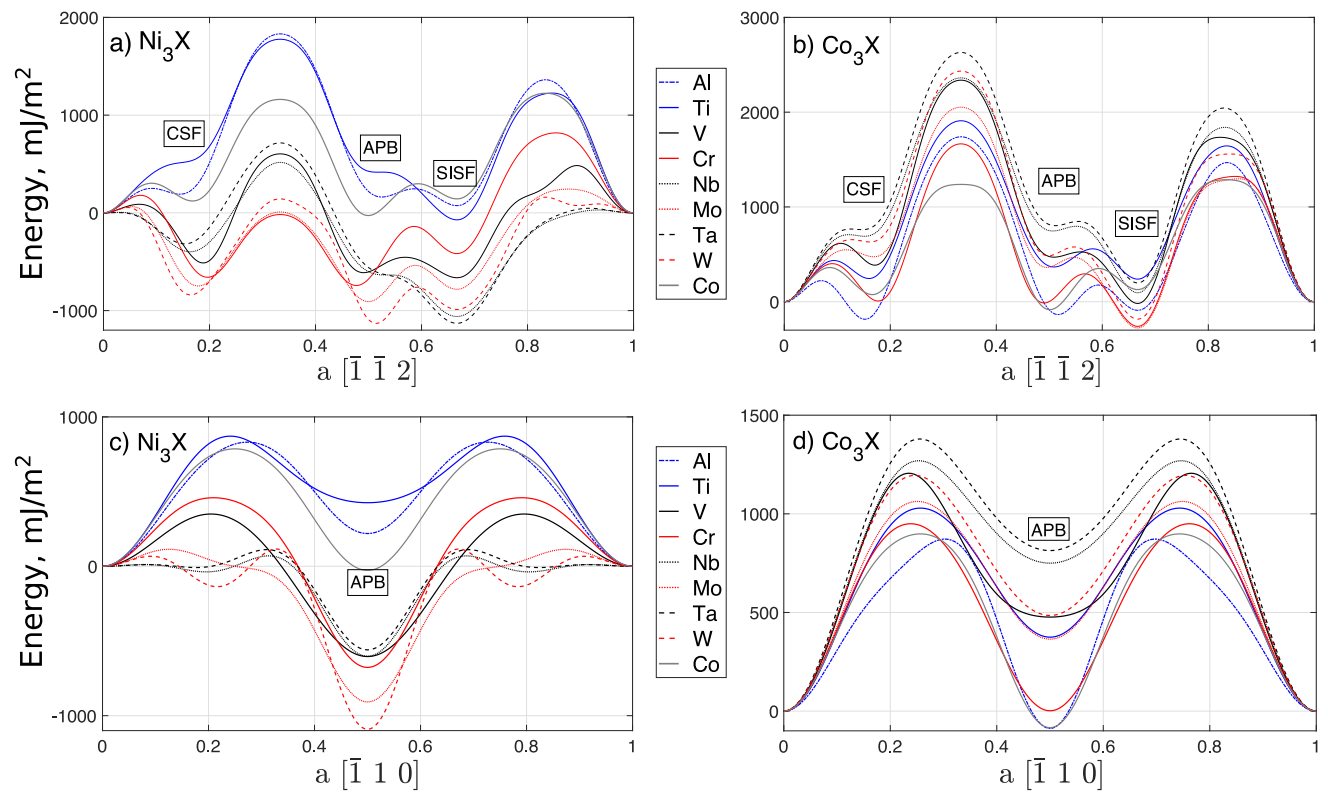

Figure 9: Figures (a) and (b) show the $\langle 112\rangle$ profiles for all Ni-based and Co-based binary compounds. For the Ni-based compounds there exist 2 distinct groups. The first consists of $\mathrm{Ni}_{3} \mathrm{Al}$ and $\mathrm{Ni}_{3} \mathrm{Ti}$ since their energy surfaces are mostly positive indicating that the $\mathrm{L}_{2}$ lattice is energetically preferable. The other compounds tend to be negative and also some do not conform to the shape of the $\Gamma$-surface that is expected. For the Co-based compounds, most of the fault energies are positive. Figures (c) and (d) show the $\langle 110\rangle$ profiles. For the Ni-based compounds, there are some compounds that do not conform to the expected shape of the $\langle 110\rangle$ profile. The black and red coloured lines correspond to systems $\left(\mathrm{A}_{3} \mathrm{~B}\right)$ that have B-type atoms in the same group of the periodic table. 

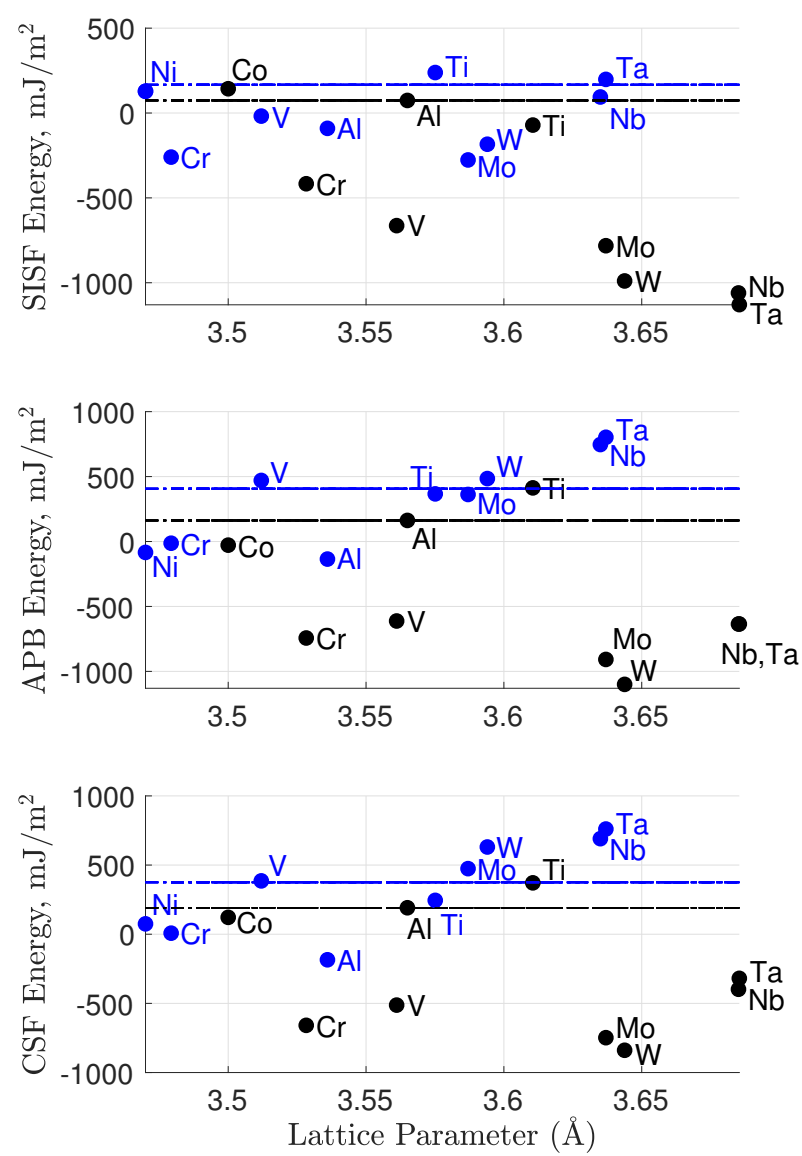

Figure 10: Variation of SISF, APB and CSF energies in $\mathrm{Co}_{3} \mathrm{X}$ and $\mathrm{Ni}_{3} \mathrm{X} \mathrm{L1} 1_{2}$ crystals with their respective lattice parameters. The blue and black dashed lines represent the fault energies of $\mathrm{Co}_{3}(\mathrm{Al}, \mathrm{W})$ and $\mathrm{Ni}_{3} \mathrm{Al}$, respectively.

\section{Supplementary information}

\section{PFMD formulation}

The model considers the temporal evolution of planar slip fields via the minimisation of free energy. The dislocation lines are defined by the diffuse boundaries between the fields as formulated by Wang et al. [6]. The total free energy of the system, $F_{\text {total }}$, includes the elastic, gradient and crystal free energy contributions:

$$
F_{\text {total }}=F_{\text {elastic }}+F_{\text {gradient }}+F_{\text {crystal }}
$$


The planar slip fields, denoted by $\eta$, have an associated stress-free transformation strain, $\varepsilon_{i j}^{0}$ :

$$
\varepsilon_{i j}^{0}=\frac{b_{i} n_{j}+b_{i} n_{j}}{2 d}
$$

where $\mathbf{b}$ and $\mathbf{n}$ are the Burgers vector and slip plane normal respectively, and $d$ is the slip plane spacing. The Khachaturyan-Shatalov theory [7] use used to calculate the elastic strain energy associated the slip fields:

$$
F_{\text {elastic }}=\frac{1}{2} \sum_{p, q=1}^{N} f B_{p q}(\mathbf{m}) \tilde{\eta}_{p}(\mathbf{k}) \tilde{\eta}_{q}^{*}(\mathbf{k}) \frac{d \mathbf{k}}{(2 \pi)^{3}}
$$

where $\mathbf{k}$ is the reciprocal space position vector sand $\mathbf{m}=\mathbf{k} /|\mathbf{k}|$ is the parallel unit vector. The tilde symbol signifies a Fourier transform of the variable and the asterisk corresponds to the complex conjugate. The integral, $f$, excludes the volume of $(2 \pi)^{3} / V$ surrounding the point $k=0$, where $V$ is the total volume of the system. The elastic kernel $B_{p q}(\mathbf{m})$ serves is evaluated as follows:

$$
B_{p q}(\mathbf{m})=\left[C_{i j k l} \varepsilon_{i j}^{0} \varepsilon_{k l}^{0}-m_{i} \sigma_{i j}^{0} \Omega_{j k}(\mathbf{m}) \sigma_{k l}^{0} m_{l}\right]
$$

with tensors $\Omega_{i j}^{-1}(\mathbf{m})=C_{i k l j} m_{k} m_{l}$ and $\sigma_{i j}^{0}=C_{i j k l} \varepsilon_{k l}^{0}$

The gradient and crystal free energy describe the dislocation core structure and the formulations used in this study were originally proposed by Shen and Wang [8, 9]:

$$
\begin{aligned}
F_{\text {gradient }}= & \frac{1}{2} \int\left[\sum_{\alpha, n_{\alpha}} \sum_{\alpha^{\prime}, n_{\alpha^{\prime}}} \beta_{\alpha, n_{\alpha}, \alpha^{\prime}, n_{\alpha^{\prime}}} \frac{\mathbf{b}_{\alpha, n_{\alpha}} \cdot \mathbf{b}_{\alpha^{\prime}, n_{\alpha^{\prime}}}}{\left|\mathbf{b}_{\alpha, n_{\alpha}}\right| \mathbf{b}_{\alpha^{\prime}, n_{\alpha^{\prime}} \mid} \mid}\right. \\
& \left.\left(\mathbf{n}_{\alpha} \times \nabla \eta_{\alpha, n_{\alpha}}\right)\left(\mathbf{n}_{\alpha^{\prime}} \times \nabla \eta_{\alpha^{\prime}, n_{\alpha^{\prime}}}\right)\right] d \mathbf{r}
\end{aligned}
$$

where the indices $\alpha$ and $n_{\alpha}$ are the slip direction and slip plane respectively, $\beta$ is the gradient energy coefficient and the prime symbol denotes the indices of a different slip system.

In turn, the crystal free energy component, $F_{\text {crystal }}$, is given by the following equation:

$$
F_{\text {crystal }}=\int \frac{\Gamma\left(\eta_{1}, \eta_{2}, \eta_{3}\right)}{d_{(111)}} \mathrm{d} \mathbf{r}
$$

where $\Gamma$ is a function describing the topography of the generalised stacking fault energy $(\Gamma-$ surface), while $\mathbf{b}_{1}=\frac{a}{2}[0 \overline{1} 1], \mathbf{b}_{2}=\frac{a}{2}[10 \overline{1}], \mathbf{b}_{3}=\frac{a}{2}[\overline{1} 10]$ and $d_{(111)}$ is the $\{111\}$ plane spacing.

Finally, the temporal evolution of the non-conserved fields $\eta$ is given by the time-dependent Ginzburg-Landau equation:

$$
\frac{\partial \eta(\mathbf{r}, t)}{\partial t}=-M \frac{\delta F_{\text {total }}}{\delta \eta(\mathbf{r}, t)}
$$

with the is a kinetic coefficient $M\left(\right.$ in $\mathrm{m}^{2} \mathrm{~N}^{-1} \mathrm{~s}^{-1}$ ) being related to the dislocation mobility, $\mathbf{r}$ - the real space position vector and $t$ - the time.

\section{$\Gamma$ surface details}

Energy calculations were performed on specific points in the $\Gamma$ surface and then fitted to a two-dimensional Fourier series, $\Gamma(x, y)$. The coordinates $x$ and $y$ are the displacement components along the $[\overline{1} \overline{1} 2]$ and [110] directions, respectively. The periodicity constants are $p=$ 
$\pi /(b \sqrt{3})$ and $q=\pi / b$ for the $\gamma^{\prime}$ phase. The periodicity in the $\gamma$ phase is half of that in the $\gamma^{\prime}$ phase, so $p=2 \pi /(b \sqrt{3})$ and $q=2 \pi / b$. The constant $b=a / \sqrt{2}$ and $a$ is the lattice parameter.

$$
\begin{aligned}
\Gamma(x, y)=c_{0} & +c_{1}[\cos (2 p x)+\cos (p x+q y)+\cos (p x-q y)] \\
& +c_{2}[\cos (2 q y)+\cos (3 p x+2 q y)+\cos (3 p x-q y)] \\
& +c_{3}[\cos (4 p x)+\cos (2 p x+2 q y)+\cos (2 p x-2 q y)] \\
& +c_{4}[\cos (5 p x+q y)+\cos (4 p x+2 q y) \\
& +\cos (p x+3 q y)+\cos (p x-3 q y) \\
& +\cos (4 p x-2 q y)+\cos (5 p x-q y)] \\
& +c_{5}[\cos (6 p x)+\cos (3 p x+3 q y)+\cos (3 p x-3 q y)] \\
& +c_{6}[\cos (4 q y)+\cos (6 p x+2 q y)+\cos (6 p x-2 q y)] \\
& +c_{7}[\cos (2 p x)+\cos (4 p x+4 q y)+\cos (4 p x-4 q y)] \\
& +c_{8}[\sin (2 p x)-\sin (p x+q y)-\sin (p x-q y)] \\
& +c_{9}[\sin (4 p x)-\sin (2 p x+2 q y)-\sin (2 p x-2 q y)] \\
& +c_{10}[\sin (5 p x+q y)-\sin (4 p x+2 q y) \\
& -\sin (p x+3 q y)-\sin (p x-3 q y) \\
& -\sin (4 p x-2 q y)+\sin (5 p x-q y)] \\
& +c_{11}[\sin (6 p x)-\sin (3 p x+3 q y)-\sin (3 p x-3 q y)] \\
& +c_{12}[\sin (8 p x)-\sin (4 p x+4 q y)-\sin (4 p x-4 q y)]
\end{aligned}
$$

The values of the coefficients, $c_{j}$ in Equation 10 are shown in Table 11 for all the systems studied. This Fourier series preserves the three-fold rotational symmetry of the $\Gamma$-surface. The following equations allow the $\Gamma(x, y)$ to be expressed in terms of the field variables as $\Gamma\left(\eta_{1}, \eta_{2}, \eta_{3}\right)$ and thus used in the PFMD:

$$
\begin{aligned}
& y=\left(-\eta_{1}+\eta_{3}\right) \sqrt{3} b / 2 \\
& z=\left(-\eta_{1}+2 \eta_{2}-\eta_{3}\right) b / 2
\end{aligned}
$$

\section{Extrapolation from experimental data and analysis}

The referenced compositional profile data were obtained by the respective authors either using high-resolution scanning transmission microscopy with energy dispersive x-ray spectroscopy or via atom probe tomography. The compositional profiles were extrapolated as numerical data from their graphs using WebPlotDigitizer software. If a compositional profile for a given element showed a peak or a dip across the locus of the fault, it was fitted using a Gaussian curve function shown below.

$$
\begin{gathered}
c_{x}=c_{\text {precip. }}+A \frac{(2 / \pi)^{\frac{1}{2}}}{w} \exp \left[-2\left(\frac{x-x_{\text {fault }}}{w}\right)^{2}\right] \\
c_{\text {fault }}=c_{\text {precip. }}+A \frac{(2 / \pi)^{\frac{1}{2}}}{w}
\end{gathered}
$$

Where $c_{x}$ is the concentration of an element at position $x$, while $A$ and $w$ are parameters related to the peak area and peak width respectively. The concentration of the element in the crystal 


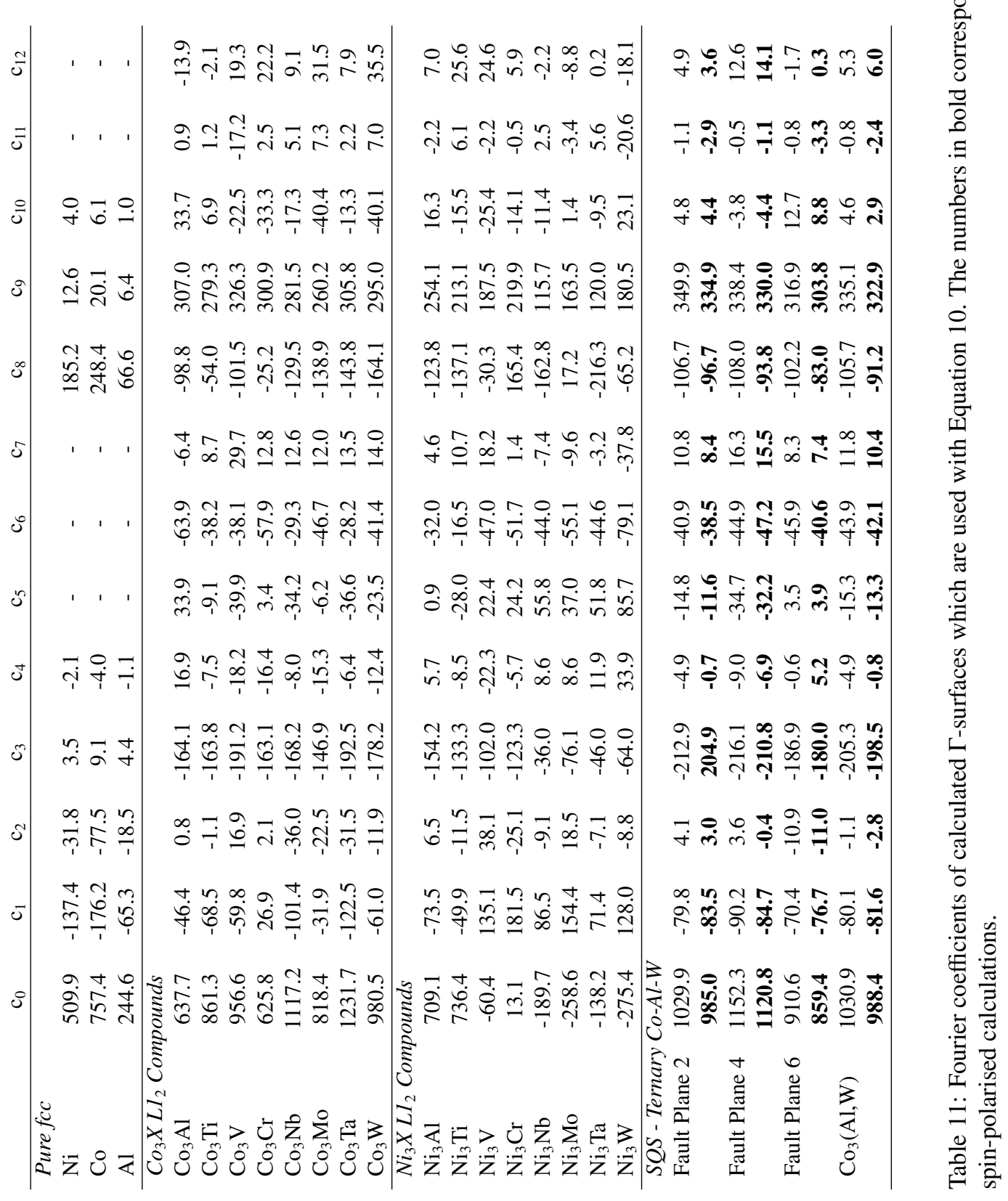


surrounding the fault is If the elemental profile showed no variation across the fault, it was fitted using a constant, i.e. $c_{x}=$ const . The curve fitting was carried out using the SciDAVis software. The fitted data for the precipitate and fault compositions were then normalised so that all the elemental concentrations added up to $100 \%$. These data are presented in Table 12

The composition data were then used to estimate the fault energy, $\Gamma$, using Vegard's law of mixtures. Two averaging schemes were used. Both schemes assumed that the A lattice site could only be occupied by either $\mathrm{Ni}$ or $\mathrm{Co}$ atoms in the $\mathrm{L}_{2} \mathrm{~A}_{3} \mathrm{~B}$ lattice. This presumed that all superalloys are a hybrid of Co-based and $\mathrm{Ni}$-based alloy properties, with proportional contributions determined by the Co:Ni ratio. The B lattice site could be occupied by Al, Cr, W, Mo, Ta, Ti or $\mathrm{Nb}$, as well as $\mathrm{Co}$ and $\mathrm{Ni}$ in the case of anti-site occupancy $\mathrm{Ni}_{3} \mathrm{Co}$ and $\mathrm{Co}_{3} \mathrm{Ni}$. Thus, averaging Scheme 1 can be summarised by the following equation:

$$
\Gamma_{\text {fault }}=\frac{c_{\mathrm{Ni}}}{c_{\mathrm{Ni}}+c_{\mathrm{Co}}} \sum_{i} \frac{c_{i} \Gamma_{\text {fault }}^{\mathrm{Ni}_{3} \mathrm{i}}}{\sum_{i} c_{i}}+\frac{c_{\mathrm{Co}}}{c_{\mathrm{Ni}}+c_{\mathrm{Co}}} \sum_{j} \frac{c_{j} \Gamma_{\text {fault }}^{\mathrm{Co}_{3} \mathrm{j}}}{\sum_{j} c_{j}}
$$

where $i=(\mathrm{Co}, \mathrm{Al}, \mathrm{Cr}, \mathrm{W}, \mathrm{Mo}, \mathrm{Ta}, \mathrm{Ti}, \mathrm{Nb})$ and $j=(\mathrm{Ni}, \mathrm{Al}, \mathrm{Cr}, \mathrm{W}, \mathrm{Mo}, \mathrm{Ta}, \mathrm{Ti}, \mathrm{Nb})$. The averaging Scheme 2 also took into account fault energies in $\mathrm{Ni}_{3} \mathrm{Ni}$ and $\mathrm{Co}_{3} \mathrm{Co}$ (i.e. pure fcc crystals), and is given by the equation below:

$$
\Gamma_{\text {fault }}=\frac{c_{\mathrm{Ni}}}{c_{\mathrm{Ni}}+c_{\mathrm{Co}}} \sum_{i} c_{i} \Gamma_{\text {fault }}^{\mathrm{N}_{3} \mathrm{i}}+\frac{c_{\mathrm{Co}}}{c_{\mathrm{Ni}}+c_{\mathrm{Co}}} \sum_{i} c_{i} \Gamma_{\text {fault }}^{\mathrm{C}_{3} \mathrm{i}}
$$

where $i=(\mathrm{Ni}, \mathrm{Co}, \mathrm{Al}, \mathrm{Cr}, \mathrm{W}, \mathrm{Mo}, \mathrm{Ta}, \mathrm{Ti}, \mathrm{Nb})$. It should be noted that for the alloy CMSX-4 the contribution of Re was ignored and the concentration of Mo was assumed to be zero. For alloy MD2, the authors did not present concentration profiles for W, Ta and Ti. Which left 4 at. $\%$ of the alloy composition unaccounted for. Using the provided nominal alloy composition, these $4 \%$ were divided proportionally between the three elements assuming that all of the $\mathrm{Ta}$ and $\mathrm{Ti}$ and half of the $\mathrm{W}$ preferentially partition to the $\gamma^{\prime}$ phase. 


\begin{tabular}{llcccccccccc} 
Alloy & Region & $\mathrm{Ni}$ & $\mathrm{Al}$ & $\mathrm{Co}$ & $\mathrm{Cr}$ & $\mathrm{W}$ & $\mathrm{Mo}$ & $\mathrm{Ta}$ & $\mathrm{Ti}$ & $\mathrm{Nb}$ & $\mathrm{Re}$ \\
\hline [59] CMSX-4 & precip. & 73.0 & 10.3 & 6.6 & 2.1 & 2.4 & - & 3.7 & 1.5 & - & 0.3 \\
& SISF & 71.3 & 9.2 & 8.0 & 3.2 & 2.9 & - & 3.7 & 1.5 & - & 0.3 \\
[59] ME3 & precip. & 70.8 & 9.0 & 9.4 & 1.5 & 0.5 & 1.0 & 0.5 & 6.9 & 0.5 & - \\
& SISF & 59.9 & 5.5 & 19.1 & 5.6 & 1.0 & 1.0 & 0.5 & 6.9 & 0.5 & - \\
[78] LSHR & precip. & 66.7 & 8.3 & 12.2 & 2.3 & 1.1 & 0.8 & - & 7.1 & 1.6 & - \\
& SISF & 64.7 & 7.6 & 14.1 & 2.7 & 1.2 & 1.0 & - & 6.9 & 1.8 & - \\
[79] CoAIW-2Ta & precip. & - & 2.1 & 72.3 & - & 20.3 & - & 5.2 & - & - & - \\
& SISF & - & 1.6 & 70.1 & - & 23.1 & - & 5.3 & - & - & - \\
[60] CoNi-A & precip. & 34.7 & 10.3 & 45.1 & 4.5 & 4.1 & - & 1.3 & - & - & - \\
& SISF & 29.6 & 8.3 & 50.4 & 5.4 & 5.1 & - & 1.3 & - & - & - \\
[80] ERBOCo-1 & precip. & 35.2 & 10.0 & 40.4 & 3.4 & 6.5 & - & 0.7 & 3.7 & - & - \\
& SISF & 33.3 & 8.6 & 42.6 & 3.6 & 7.4 & - & 0.8 & 3.7 & - & - \\
\hline [81] MD2 & precip. & 79.3 & 10.0 & 4.3 & 2.2 & 1.1 & 0.1 & 1.6 & 1.4 & - & - \\
& APB & 78.0 & 9.0 & 5.0 & 3.5 & 1.1 & 0.4 & 1.6 & 1.4 & - & - \\
[60] CoNi-A & precip. & 35.1 & 10.1 & 45.3 & 4.3 & 4.0 & - & 1.3 & - & - & - \\
& APB & 27.9 & 7.3 & 51.5 & 9.2 & 3.3 & - & 0.7 & - & - & - \\
\hline
\end{tabular}

Table 12: Normalised compositions (at.\%) extrapolated from experimental mapping across SISFs and APBs and the surrounding $\gamma^{\prime}$ host crystal. 


\section{Bibliography}

\section{References}

[1] R. Reed, The Superalloys: Fundamentals and Applications Cambridge University Press, 2006.

[2] J. Sato, T. Omori, K. Oikawa, I. Ohnuma, R. Kainuma, K. Ishida, Cobalt-base high-temperature alloys, Science 312 (5770) (2006) 90-91.

[3] I. Barnes, Operating experience of low grade fuels in circulating fluidised bed combustion IEA Clean Coal Centre. (2015)

[4] V. Vitek, On the Stability of Stacking Faults in B.C.C. Crystals. Philos. Mag. 21 (1970) 1275-1281.

[5] T. L. Achmad, W. Fu, H. Chen, C. Zhang, Z. G. Yang, Effects of alloying elements concentrations and temperatures on the stacking fault energies of Co-based alloys by computational thermodynamic approach and first-principles calculations J. Alloy. Compd. 694 (2017) 1265-1279.

[6] Y. Wang, Y. Jin, A. Cuitiño, A. Khachaturyan, Nanoscale phase field microelasticity theory of dislocations: model and 3d simulations. Acta Mater. 49 (10) (2001) $1847-1857$.

[7] A. G. Khachaturyan, G. A. Shatalov, Theory of macroscopic periodicity for a phase transition in the solid state, Sov. Phys. JETP - USSR 29 (1969) 557-561.

[8] C. Shen, Y. Wang, Phase field model of dislocation networks, Acta Mater. 51 (9) (2003) 2595-2610.

[9] C. Shen, Y. Wang, Incorporation of $\gamma$-surface to phase field model of dislocations: Simulating dislocation dissociation in fcc crystals, Acta Mater. 52 (3) (2004) 683-691.

[10] V. Vorontsov, C. M. F. Rae, C. Shen, Y. Wang, D. Dye, Shearing of $\gamma^{\prime}$ precipitates by $a(112)$ dislocation ribbons in Ni-base superalloys: A phase field approach, Acta Mater. 58 (12) (2010) 4110-4119.

[11] V. Vorontsov, R. Voskoboinikov, C. M. Rae, Prediction of Mechanical Behaviour in Ni-Base Superalloys Using the Phase Field Model of Dislocations, Adv. Mat. Res. 278 (2011) 150-155.

[12] V. Vorontsov, R. E. Voskoboinikov, C. M. Rae, Shearing of $\gamma^{\prime}$ precipitates in Ni-base superalloys: A phase field study incorporating the effective $\gamma$-surface, Philos. Mag. 92 (5) (2012) 608-634.

[13] L. Feng, D. Lv, R.K. Rhein, J.G. Goiri, M.S. Titus, A. Van der Ven, T.M. Pollock, Y. Wang, Shearing of $\gamma^{\prime}$ particles in Co-base and Co-Ni-base superalloys, Acta Mater. 161 (2018) 99-109.

[14] A.T. Paxton, Electron Theory in Alloy Design, edited by DG Pettifor and AH Cottrell (London: Institute of Materials), 1992.

[15] C. Brandl, P. Derlet, H. Van Swygenhoven, General-stacking-fault energies in highly strained metallic environments: Ab initio calculations, Phys. Rev. B. 76 (5) (2007) 1-8.

[16] A. Hunter, R. F. Zhang, I. J. Beyerlein, The core structure of dislocations and their relationship to the material $\gamma$-surface J. Appl. Phys. 115 (13) (2014) 134314.

[17] T. L. Achmad, W. Fu, H. Chen, C. Zhang, Z. G. Yang, First-principles calculations of generalized-stacking-faultenergy of Co-based alloys Comp. Mater. Sci. 121 (2016) 86-96.

[18] H. Van Swygenhoven, P. M. Derlet, a. G. Frøseth, Stacking fault energies and slip in nanocrystalline metals. Nat. Mater. 3 (6) (2004) 399-403.

[19] G. Schoeck, The core structure of dissociated dislocations in NiAl Acta Mater. 49 (7) (2001) 1179-1187.

[20] R. E. Voskoboinikov, Effective $\gamma$-surfaces in $\{111\}$ plane in FCC Ni and $\mathrm{L1}_{2} \mathrm{Ni}_{3} \mathrm{Al}$ intermetallic compound Phy. of Met. Metall. 114 (7) (2013) 545-552.

[21] S. Clark, M. Segall, C. Pickard, P. Hasnip, M. Probert, K. Refson, M. Payne, First principles methods using CASTEP Z. Kristallogr. 220 (5-6) (2005) 567-570.

[22] D. Vanderbilt, Soft self-consistent pseudopotentials in a generalized eigenvalue formalism Phys. Rev. B. 41 (1990) 7892-7895.

[23] J. P. Perdew, K. Burke, M. Ernzerhof, Generalized gradient approximation made simple Phys. Rev. Lett. 77 (1996) 3865-3868.

[24] R. Martin, Electronic Structure Basic Theory and Practical Methods, Cambridge University Press, 2004.

[25] H. Monkhorst, J. Pack, Special points for Brillouin-zone integrations Phys. Rev. B 13 (1976) 5188-5192.

[26] M. Methfessel, A. Paxton, High-precision sampling for Brillouin-zone integration in metals Phys. Rev. B 40 (1989) 3616-3621.

[27] P. Pulay, Convergence acceleration of iterative sequences. The case of SCF iteration Chem. Phys. Lett. 73 (2) (1980) $393-398$.

[28] M. J. Besnus, Y. Gottehrer, G. Munschy, Magnetic Properties of Ni-Cr Alloys Phys. Status Solidi (b) 49 (1972) 597.

[29] H. Gholizadeh, C. Draxl, P. Puschnig, The influence of interstitial carbon on the $\gamma$-surface in austenite Acta Mater. 61 (1) (2013) 341-349.

[30] G. Schoeck, The dissociation energy of extended dislocations in fcc lattices Phil. Mag. A 79 (5) (1999) 1207-1215. 
[31] A. Zunger, S. H. Wei, L. G. Ferreira, J. E. Bernard, Special quasirandom structures, Phys. Rev. Lett. 65 (3) (1990) $353-356$.

[32] S. H. Wei, L. G. Ferreira, J. E. Bernard, A. Zunger, Electronic properties of random alloys: Special quasirandom structures, Phys. Rev. B 42 (15) (1990) 9622-9649.

[33] B. E. Tegner, L. Zhu, G. J. Ackland, Relative strength of phase stabilizers in titanium alloys , Phys. Rev. B 85 (2012) 214106.

[34] A. Van de Walle, G. Ceder, Automating first-principles phase diagram calculations, J. Phase Equilib. 23 (4) (2002) $348-359$.

[35] A. Van de Walle, M. Asta, Self-driven lattice-model Monte Carlo simulations of alloy thermodynamic properties and phase diagrams, Model Simul. Mater. Sc. 10 (5) (2002) 521-538.

[36] A. Van de Walle, P. Tiwary, M. de Jong, D. Olmsted, M. Asta, A. Dick, D. Shin, Y. Wang, L.-Q. Chen, Z.-K. Liu, Efficient stochastic generation of special quasirandom structures Calphad 42 (2013) $13-18$.

[37] G. L. W. Hart, R. W. Forcade, Algorithm for generating derivative structures Phys. Rev. B 77 (2008) 224115.

[38] A. Van de Walle, Multicomponent multisublattice alloys, nonconfigurational entropy and other additions to the Alloy Theoretic Automated Toolkit, Calphad 33 (2) (2009) 266-278.

[39] M. Chandran, S. Sondhi, First-principle calculation of stacking fault energies in Ni and Ni-Co alloy, J. Appl. Phys. 109 (10) (2011)

[40] J. Zimmerman, H. Gao, F. Abraham, Generalized stacking fault energies for embedded atom FCC metals, Model Simul. Mater. Sc. 8 (2) (2000) 103-115.

[41] N. Rosengaard, H. Skriver, Calculated stacking-fault energies of elemental metals, Phys. Rev. B 47 (1993) 865-873.

[42] C. Woodward, D. R. Trinkle, L. G. Hector, D. L. Olmsted, Prediction of dislocation cores in aluminum from density functional theory, Phys. Rev. Letters 100 (4) (2008) 1-4.

[43] G. Lu, N. Kioussis, V. V. Bulatov, Generalized-stacking-fault energy surface and dislocation properties of aluminum, Phys. Rev. B. - Condensed Matter and Materials Physics 62 (5) (2000) 3099-3108.

[44] V. A. de la Pea OShea, I. d. P. R. Moreira, A. Roldn, F. Illas, Electronic and magnetic structure of bulk cobalt: The $\alpha, \beta$, and $\epsilon$-phases from density functional theory calculations The Journal of Chemical Physics 133 (2) (2010) 024701. ,

[45] S. Sahoo, A. Hucht, M. E. Gruner, G. Rollmann, P. Entel, A. Postnikov, J. Ferrer, L. Fernández-Seivane, M. Richter, D. Fritsch, S. Sil, Magnetic properties of small pt-capped fe, co, and ni clusters: A density functional theory study Phys. Rev. B 82 (2010) 054418.

[46] O. N. Mryasov, Y. N. Gornostyrev, M. Van Schilfgaarde, A. J. Freeman, Superdislocation core structure in L1 $\mathrm{Ni}_{3} \mathrm{Al}, \mathrm{Ni}_{3} \mathrm{Ge}$ and $\mathrm{Fe}_{3} \mathrm{Ge}$ : Peierls-Nabarro analysis starting from ab-initio GSF energetics calculations, Acta Mater. 50 (18) (2002) 4545-4554.

[47] G. Schoeck, S. Kohlhammer, M. Fahnle, Planar dissociations and recombination energy of [110] superdislocations in $\mathrm{Ni}_{3} \mathrm{Al}$ : Generalised Peierls model in combination with ab initio electron theory, Philos. Mag. Lett. 79 (11) (1999) 849-857.

[48] K. V. Vamsi, S. Karthikeyan, Effect of off-stoichiometry and ternary additions on planar fault energies in $\mathrm{Ni}_{3} \mathrm{Al}_{\text {, }}$ Superalloys 2012: 12th International Symposium on Superalloys 3 (c) (2012) 521-530.

[49] J. E. Saal, C. Wolverton, Energetics of antiphase boundaries in $\gamma^{\prime} \mathrm{Co}_{3}(\mathrm{Al}, \mathrm{W})$-based superalloys Acta Mater. 103 (2016) 57-62.

[50] A. Mottura, A. Janotti, T. M. Pollock, A first-principles study of the effect of Ta on the superlattice intrinsic stacking fault energy of $\mathrm{L1}_{2}-\mathrm{Co}_{3}(\mathrm{Al}, \mathrm{W})$ Intermetallics 28 (2012) 138-143.

[51] K. V. Vamsi, S. Karthikeyan, Yield anomaly in $\mathrm{L1}_{2} \mathrm{Co}_{3} \mathrm{Al}_{x} \mathrm{~W}_{1-x}$ vis-a-vis $\mathrm{Ni}_{3} \mathrm{Al}$, Scripta Mater. 130 (2017) 269 273.

[52] G. R. Leverant, B. H. Kear, J. M. Oblak, Creep of precipitation-hardened nickel-base alloy single crystals at high temperatures Metall. Transac. 4 (1) (1973) 355-362.

[53] T. Pollock, A. Argon, Creep resistance of CMSX-3 nickel base superalloy single crystals Acta Metall. 40 (1) (1992) 1-30.

[54] M. S. Titus, Y. M. Eggeler, A. Suzuki, T. M. Pollock, Creep-induced planar defects in L1 ${ }_{2}$-containing Co- and CoNi-base single-crystal superalloys Acta Mater. 82 (2015) 530-539.

[55] D. Hull, J. Bacon, D, Introduction to Dislocations, 5th Edition, Elsevier B.V, 2009.

[56] M. Yamaguchi, V. Vitek, D. P. Pope, Planar faults in the $\mathrm{L} 1_{2}$ lattice: stability and structure Phil. Mag. A 43 (4) (1981) 1027-1044.

[57] F. Birch, Finite elastic strain of cubic crystals. Phys. Rev. 71 (1947) 809-824.

[58] M. Chen, First-principle investigation of 3d transition metal elements in $\gamma^{\prime}-\mathrm{Co}_{3}(\mathrm{Al}, \mathrm{W})$, J. Appl. Phys. 107 (2010)

[59] G. B. Viswanathan, R. Shi, A. Genc, V. A. Vorontsov, L. Kovarik, C. M. F. Rae, M. J. Mills, Segregation at stacking faults within the $\gamma^{\prime}$ phase of two Ni-base superalloys following intermediate temperature creep. Scripta Mater. 94 (2015) 5-8.

[60] Y. Eggeler, J. Müller, M. Titus, A. Suzuki, T. Pollock, E. Spiecker, Planar defect formation in the gamma phase 
during high temperature creep in single crystal CoNi-base superalloys Acta Mater. 113 (2016) 335-349.

[61] M. Lenz, Y.M. Eggeler, J. Müller, C.H. Zenk, N. Volz, P. Wollgramm, G. Eggeler, S. Neumeier, M. Göcken, P. Spiecker, Tension/compression asymmetry of a creep deformed single crystal Co-base superalloy Acta Mater. 166 (2019) 597-610.

[62] S. Meher, H. Y. Yan, S. Nag, D. Dye, R. Banerjee, Solute partitioning and site preference in $\gamma / \gamma^{\prime}$ cobalt-base alloys Scripta Mater. 67 (10) (2012) 850-853.

[63] M. S. Titus, A. Mottura, G. Babu Viswanathan, A. Suzuki, M. J. Mills, T. M. Pollock, High resolution energy dispersive spectroscopy mapping of planar defects in $\mathrm{L1}_{2}$-containing Co-base superalloys Acta Mater. 89 (2015) $423-437$.

[64] M.S. Titus, R.K. Rhein, P.B. Wells, P.C. Dodge, G.B. Viswanathan, M.J. Mills, A. Van der Ven, T.M. Pollock, Solute segregation and deviation from bulk thermodynamics at nanoscale crystalline defects, Sci. Adv. 2 (2016) e1601796.

[65] J. E. Saal, C. Wolverton, Thermodynamic stability of Co-Al-W L1 $2 \gamma^{\prime}$ Acta Mater. 61 (7) (2013) 2330-2338.

[66] F. Xue, M. Wang, Q. Feng, Alloying Effects on Heat Treated Microstructure in Co Al W Base Superalloys at $1300^{\circ}$ $\mathrm{C}$ and $900^{\circ} \mathrm{C}$ Superalloys 2012 (2012) 813-821.

[67] F. D. Murnaghan, The compressibility of media under extreme pressures P. Natl. Acad. Sci, USA 30 (9) (1944) 244-247.

[68] S. Shang, A. Saengdeejing, Z. Mei, D. Kim, H. Zhang, S. Ganeshan, Y. Wang, Z. Liu, First-principles calculations of pure elements: Equations of state and elastic stiffness constants Comp. Mater. Sci. 48 (4) (2010) 813-826.

[69] F. X. Kayser, C. Stassis, The elastic constants of $\mathrm{Ni}_{3} \mathrm{Al}$ at 0 and $23.5^{\circ} \mathrm{C}$, Phys. Status Solidi (a) 64 (1) (1981) 335-342.

[70] C. Jiang, First-principles study of $\mathrm{Co}_{3}(\mathrm{Al}, \mathrm{W})$ alloys using special quasi-random structures Scripta Mater. 59 (10) (2008) 1075-1078.

[71] D. Siegel, Generalized stacking fault energies, ductilities, and twinnabilities of $\mathrm{Ni}$ and selected Ni alloys, Appl. Phys. Lett. 87 (12) (2005) 1-3.

[72] Y. Rao, T. M. Smith, M. J. Mills, M. Ghazisaeidi,Segregation of alloying elements to planar faults in $\gamma^{\prime}-\mathrm{Ni}_{3} \mathrm{Al}$, Acta Mater. 148 (2018) 173-184.

[73] W. W. Xu, J. J. Han, Z. W. Wang, C. P. Wang, Y. H. Wen, X. J. Liua, and Z. Z. Zhu. Thermodynamic, structural and elastic properties of $\mathrm{Co} 3 \mathrm{X}(\mathrm{X}=\mathrm{Ti}, \mathrm{Ta}, \mathrm{W}, \mathrm{V}, \mathrm{Al})$ compounds from first-principles calculations. Intermetallics, 32:303-311, 2013.

[74] V. K. Portnoi, K. V. Tret'yakov, and V. I. Fadeeva. Structural transformations during the mechanochemical synthesis and heating of Co-Al alloys. Inorganic Materials, 40(9):937-944, 2004.

[75] A. Breidi, J. Allen, and A. Mottura. First-principles calculations of thermodynamic properties and planar fault energies in $\mathrm{Co}_{3} \mathrm{X}$ and $\mathrm{Ni}_{3} \mathrm{X} \mathrm{L1}_{2}$ compounds. Phys. Status Solidi (b), 2017.

[76] X. He, L. T. Kong, and B. Liu. Stability of the Metastable Phases in the Co-Ta System Studied by ab initio and Thermodynamic Calculations Together with Ion-Beam-Mixing Experiment. J. Phys. Soc. J., 74(9):2501-2505, 2005.

[77] P. V. M. Rao, K. S. Murthy, S. V. Suryanarayana, and S. V. N. Naidu. Effect of Ternary Additions on the RoomTemperature Lattice-Parameter of $\mathrm{Ni}_{3}$ al. Phys. Status Solidi a, 133(2):231-235, 1992.

[78] T. M. Smith, B. S. Good, T. P. Gabb, B. D. Esser, A. J. Egan, L. J. Evans, D. W. McComb, M. J. Mills, Effect of stacking fault segregation and local phase transformations on creep strength in Ni-base superalloys Acta Mater. 172 (2019) 55-65.

[79] N. S. Titus, A. Suzuki, M. J. Mills, T. M. Pollock, Sub-nanometer resolution Chemi-STEM EDS mapping of intrinsic stacking faults in Co-based superalloys Microsc. Microanal. 20 (Suppl. 3) (2014) 1028-1029.

[80] S. K. Makineni, A. Kumar, M. Lenz, P. Kontis, T. Meiners, C. Zenk, S. Zaefferer, G. Eggeler, S. Neumeier, E. Spiecker, D. Raabe, B. Gault, On the diffusive phase transformation mechanism assisted by extended dislocations during creep of a single crystal CoNi-based superalloy Acta Mater. 155 (2018) 362-371.

[81] D. Barba, T. M. Smith, J. Miao, M. J. Mills, R. C. Reed, Segregation-assisted plasticity in Ni-based superalloys Metall. Mater. Trans. A 49 (2018) 4173-4185. 